University of Wollongong

Research Online

Faculty of Engineering and Information

Faculty of Engineering and Information

Sciences - Papers: Part A

Sciences

$1-1-2015$

\title{
Observed and predicted behaviour of rail ballast under monotonic loading capturing particle breakage
}

Buddhima Indraratna

University of Wollongong, indra@uow.edu.au

Qi Deng Sun

University of Wollongong, qs349@uowmail.edu.au

Sanjay Nimbalkar

University of Wollongong, sanjayn@uow.edu.au

Follow this and additional works at: https://ro.uow.edu.au/eispapers

Part of the Engineering Commons, and the Science and Technology Studies Commons

Research Online is the open access institutional repository for the University of Wollongong. For further information contact the UOW Library: research-pubs@uow.edu.au 


\title{
Observed and predicted behaviour of rail ballast under monotonic loading capturing particle breakage
}

\author{
Abstract \\ A substantial amount of experimental evidence suggests that the critical state envelope for ballast is \\ nonlinear, especially at low confining pressure. To study the implications of this nonlinearity and the \\ associated role of particle breakage, monotonically loaded drained triaxial tests were conducted using a \\ large-scale cylindrical triaxial apparatus. A nonlinear critical state envelope is determined in the $q-p=$ and \\ -Inp= planes. Mathematical expressions for critical state stress ratio and specific volume are proposed to \\ incorporate the evolution of particle breakage during monotonic shearing. In this paper, an elastoplastic \\ constitutive model based on the critical state soil mechanics framework is presented to capture the \\ salient aspects of stress- strain behaviour and degradation of ballast. Constitutive parameters were \\ conveniently determined from large-scale laboratory tests. The model is able to predict the monotonic \\ shear behaviour of ballast corroborating with the laboratory measurements. The proposed model is \\ further validated using experimental results available from past independent studies.

\section{Disciplines} \\ Engineering | Science and Technology Studies

\section{Publication Details} \\ Indraratna, B., Sun, Q. \& Nimbalkar, S. (2015). Observed and predicted behaviour of rail ballast under \\ monotonic loading capturing particle breakage. Canadian Geotechnical Journal, 52 (1), 73-86.
}




\section{Observed and predicted behaviour of rail ballast under}

\section{monotonic loading capturing particle breakage}

Buddhima Indraratna, PhD (Alberta), FTSE, FIEAust., FASCE, FGS

Professor of Civil Engineering and Research Director,

Centre for Geomechanics and Railway Engineering;

Program Leader, ARC Centre of Excellence for Geotechnical Science and Engineering;

University of Wollongong, Wollongong, NSW 2522, Australia.

E-mail: indra@uow.edu.au

Qi Deng Sun, BEng, MEng (Tongji University)

PhD Candidate, Faculty of Engineering,

University of Wollongong, Wollongong NSW 2522, Australia.

E-mail: qs349@uowmail.edu.au

Sanjay Nimbalkar, PhD (IIT-Bombay)

Research Fellow, Centre for Geomechanics and Railway Engineering;

ARC Centre of Excellence for Geotechnical Science and Engineering;

University of Wollongong, Wollongong, NSW 2522, Australia.

E-mail: sanjayn@uow.edu.au

Words: 5085; Figures: 15; Tables: 2; Date of Submission: 15/05/2014

Submitted to: Canadian Geotechnical Journal

Author for correspondence:

Prof. Buddhima Indraratna,

University of Wollongong,

Wollongong, NSW 2522, Australia.

Ph: +61242213046

Fax: +61242213238

Email: indra@uow.edu.au 
Abstract: A substantial amount of experimental evidence suggests that the critical state envelope for ballast is non-linear, especially at low confining pressure. In order to study the implications of this non-linearity and the associated role of particle breakage, monotonically loaded drained triaxial tests were conducted using the large-scale cylindrical triaxial apparatus. A non-linear critical state envelope is determined in the $q-p^{\prime}$ and $v-\ln p^{\prime}$ planes. Mathematical expressions for critical state stress ratio and specific volume are proposed to incorporate the evolution of particle breakage during monotonic shearing. In this paper, an elasto-plastic constitutive model based on the critical state soil mechanics framework is presented to capture the salient aspects of stress-strain behaviour and degradation of ballast. Constitutive parameters were conveniently determined from large-scale laboratory tests. The model is able to predict the monotonic shear behaviour of ballast corroborating with the laboratory measurements. The proposed model is further validated using experimental results available from past independent studies.

Key words: particle breakage, critical state, Non-linearity, ballast, constitutive modelling. 


\section{Introduction}

It is found that the breakage of particles influences the strength and deformation behaviour of rail ballast (Indraratna et al. 1998, 2005; Indraratna and Salim 2002; Lackenby et al. 2007; Nimbalkar et al. 2012). It is well-established in granular media that when grain breakage occurs, the internal angle of friction and the associated dilation angle decrease, while facilitating further compression (Marsal 1967; Marachi et al. 1972; Chales and Watts 1980; Lade et al. 1996; Ueng and Chen 2000; Indraratna et al. 2011; Indraratna and Nimbalkar 2013). Larger particle sizes with high grain angularity increase the extent of particle breakage during dilation (Lee and Farhoomand 1967; McDowell and Bolton 1998; Indraratna and Salim 2002; Lackenby 2006; Lackenby et al. 2007). It has been reported that highly angular aggregates break easily at the corners even at small confining pressures leading to a significant reduction of the friction angle (Marsal 1967; Marachi et al. 1972; Indraratna et al. 2011). The presence of micro-fissures in blasted and quarried aggregates also exacerbate breakage during shearing (Marsal 1967; Lade et al. 1996). Indraratna et al. (1998) through extensive large scale triaxial testing of latite basalt aggregates provided a non-linear empirical relationship $\phi_{p}^{\prime}=j\left(B_{g}\right)^{k}$, where $\phi_{p}^{\prime}$ is the peak angle of friction, $B_{g}$ is Marsal's breakage index (Marsal, 1967), $j$ (64.84 to 73.19$)$ and $k(-0.13$ to -0.18$)$ are empirical parameters. This empirical equation has been derived at relatively large axial strains (@ 20-25\%) and it represents the reduction in friction angle with increasing particle breakage. For example in the case of latite basalt, the increase in Marsal's breakage index from $5 \%$ to $10 \%$ is associated with a reduction in friction angle of about $7-12^{\circ}$ depending on the initial particle size distribution (PSD), where a PSD containing larger size aggregates indicates greater vulnerability to breakage. The test results by the previous studies conducted by the first author and co-workers do support the claim that even at large axial strains exceeding say 20$25 \%$ (i.e. approaching a state of little or no volume change), the continual breakage of 
particles will cause reduced angularity, and this in turn would effect a reduced critical state friction angle. This will be associated with a corresponding change in the critical state parameter, $M_{c}\left(M_{c}=6 \sin \phi_{c s} /\left(3-\sin \phi_{c s}\right)\right)$. It has also been reported by others that the decrease in the value of $M_{c}$ is mainly attribute to both confining pressure and particle breakage (Chavez and Alonso 2003; Cheng et al. 2005). This may be in some conflict with the past studies (Coop 1990; Mooney et al. 1998; Coop et al. 2004; Bandini and Coop 2011). The studies of Coop (1990), and Bandini \& Coop (2011) conducted on much finer granular materials compared to rail ballast indicate that in spite of excessive breakage, the critical state stress ratio Mc remains relatively constant at high confining pressure, and very large amounts of breakage in shearing had little effect on Mc (Coop et al. 2004). However, as described earlier and observed in other studies, the rate and extent of breakage of very coarse and highly angular particles such as rail ballast should not be directly compared with much finer grained materials such as sand, which may require higher applied stresses to initiate significant breakage (e.g. Lade et al. 1996; Russel and Khalili 2004). Also, ballast has very different physical and mechanical properties (size and shape of particles, surface texture, inter-particulate friction, micro-fractures (due to blasting) etc.).

Been et al. (1991) investigated the critical state of sands for a wide range of confining stresses and proposed a bilinear critical state line (CSL). Russell and Khalili (2004) described the behaviour of crushable granular materials using a three-segment CSL within a boundary surface constitutive model. Bedin et al. (2012) through a series monotonic triaxial testing on gold tailings observed a highly non-linear shape of CSL and stated that the curvature was due to particle breakage. Daouadji et al. (2001) represented the position of the CSL in terms of the amount of energy needed for grain breakage, showing that the CSL in the e-lnp' domain descends according to the evolution of particle gradation. Muir Wood and Maeda (2008) proposed a model for sands in which a series of critical state lines in the $e$ - $\ln p^{\prime}$ plane are 
related to the current grading of the soil. As particle breakage occurs, the grading index $I_{g}$ increase, it is assumed the current critical state line moves downwards towards a limiting critical state line at the limiting grading. It is therefore assumed that the effects of breakage are to move the critical state line continually downwards. The downward shift of the CSL on the $e$-lnp' plane can be attributed to the smaller broken grains which then rearrange to a more compact state attaining a lower void ratio, e (e.g. Russel and Khalili 2004; Bedin et al. 2012). Banidi and Coop (2011) also suggested that the influence of the newly created small fragments on CSL was not very large as the latter was insensitive to the new grading as assumed in the study by Muir Wood and Maeda (2008). Significant stress concentrations and attrition in coarse and highly angular particles of ballast lead to considerable breakage of asperities and sharp corners at relatively low stresses (Lackenby et al. 2007; Indraratna et al. 2014). Even though the overall volume of breakage of relatively softer materials (e.g. carbonate sands, weathered sandstone) can be higher, the effect of degradation on the properties of ballast is mainly governed by the sharp drop of angularity upon breakage (Indraratna et al., 2011). Therefore, findings on carbonate sand reported by Bandini \& Coop (2011) and Coop et al. (2004) may not be directly applicable to ballast, including the behaviour implied at the critical state.

Indraratna et al. (2005) introduced a breakage index specifically for railway ballast to quantify the magnitude of degradation. The evaluation of the ballast breakage index (BBI) employs the change in the fraction passing a range of sieve sizes. Figure 1 illustrates the definition of BBI. In this paper, the critical state of ballast is investigated by large-scale triaxial tests, where particle breakage was quantified using the BBI. The particle breakage during triaxial shearing is modelled by a nonlinear function which links BBI with the accumulated plastic deviatoric strain $\left(\varepsilon_{s}^{p}\right)$ and initial effective mean stress $p_{i}^{\prime}$. Hence, it is possible to predict the evolution of BBI at each stage of loading, whereby BBI is captured in 
the CSL in both $q-p^{\prime}$ and $v$-lnp' planes. Inspired by the laboratory observations, an elastoplastic state-dependent constitutive model under triaxial monotonic loading is formulated.

\section{Experimental program, test results and discussions}

\section{Sample preparation and testing}

Latite basalt, a commonly used ballast in the state of New South Wales, Australia, was used in this study. It was thoroughly cleaned, dried and sieved through a set of 12 standard sieves (aperture size 53: $2.36 \mathrm{~mm}$ ). Figure 2 shows the particle size distribution (PSD) curve adopted here representing the current Australia practices (Standards Australia 1996). Particles from each size range were weighed separately and mixed thoroughly before placing them inside a $7 \mathrm{~mm}$ thick rubber membrane in four separate layers, where each layer was compacted with a plate vibrator to a density of $1530 \mathrm{~kg} / \mathrm{m}^{3}$. Compaction was facilitated by a split cylindrical mould which was removed before the specimen was placed inside the cell pressure chamber. Prior to testing, each specimen was subjected to an upward flow of water from the bottom plate under a back pressure of $10 \mathrm{kPa}$. The specimen was allowed to saturate overnight until a Skempton's $B$ value of 0.97-0.98 was achieved for typical compacted ballast with an initial void ratio of around 0.76 . Before shearing, the specimens were isotropically consolidated at confining pressures of 30-570 $\mathrm{kPa}$ (Table 1).

The confining pressure was increased in several steps to a constant preselected value, and the corresponding change in volume of the specimen was then recorded. Fully drained compression tests were conducted at an axial strain rate of $3 \mathrm{~mm} / \mathrm{min}$, which prevented any build-up of excess pore water pressure. The load cell, pressure transducers and LVDTs were connected to a computer-controlled data acquisition system. Shearing was continued until the samples either reached their critical states or until the vertical strain reached the maximum 
strain capacity of $30 \%$. Membrane correction has been applied to the current stress measurements, in accordance with the hoop stress theory discussed by Henkel and Gilbert (1952). The additional radial stress due to membrane confinement is considered in correcting the measured deviator stress and mean stress. At the lowest confining pressure $\left(\sigma_{3}{ }^{\prime}=30 \mathrm{kPa}\right)$, the maximum correction for $7 \mathrm{~mm}$ thick rubber membrane was less than $5 \%$, hence this has little effect on the data interpretation and the final conclusions. Upon completion of each test, the specimens were sieved to determine the extent of breakage using BBI.

\section{Stress-strain-volume change behaviour of ballast}

Figure 3(a) shows the measured deviatoric stress $q$ versus the deviatoric strain at the range of confining pressures adopted in the present study. It is observed that $q$ initially increases with increasing deviator strain until it reaches the peak value. Apparently, for a higher confining pressure, the peak value of $q$ becomes higher. In Fig. 3(b), the deviatoric strain is depicted versus the volumetric strain. It is seen that at relatively low confining pressure $\left(\sigma_{3^{\prime}} \leq 60 \mathrm{kPa}\right)$, the volumetric strain is initially compressive but it swiftly becomes dilative with the increasing deviatoric strain. As the confining pressure increases, the rate of dilation diminishes as expected. At elevated confining pressure $\left(\sigma_{3^{\prime}} \geq 240 \mathrm{kPa}\right)$, the overall volumetric response is compressive. Unlike fine-grained materials such as sand and clay, no distinct shear plane could be observed in coarse aggregates such as rail ballast when tested in largescale triaxial apparatus even at low confining pressure. The failure was accompanied by specimen 'bulging' (Lackenby et al. 2007) and subsequent gradual strain softening over a large axial strain up to $30 \%$ (limit of the equipment), with many samples reaching a critical state (i.e. almost constant volumetric strain).

\section{Modelling of particle breakage}


Indraratna and Salim (2002) demonstrated with experimental evidence that the particle breakage increases with increasing axial strain, but at a decreasing rate, finally approaching a relatively constant value. The value of breakage index also becomes greater as the confining pressure increases. From these experimental findings, a unified function is proposed as following to represent the particle breakage during shearing:

$$
B B I=\frac{\theta_{b}\left[1-\exp \left(-v_{b} \varepsilon_{s}^{p}\right)\right]}{\omega_{b}-\ln p_{i}^{\prime}}
$$

where, $\theta_{b}, v_{b}$ and $\omega_{b}$ are material constants characterising the breakage of aggregates, and $p_{i}{ }^{\prime}$ is the initial effective mean stress.

\section{The critical state of ballast considering particle breakage effect}

Triaxial tests were conducted at relatively large axial strain (maximum 30\%) to investigate the critical state of railway ballast under a wide range of confining pressure $\left(30 \leq \sigma_{3}{ }^{\prime} \leq 570\right.$ $\mathrm{kPa}$ ). Figure 3(b) shows that 'constant volume' values corresponding to the critical state were observed for the tests conducted at $\sigma_{3}{ }^{\prime} \geq 180 \mathrm{kPa}$. For specimens subjected to $\sigma_{3}{ }^{\prime}=30$ and 60 $\mathrm{kPa}$ testing could not be continued until the critical state due to the actuator's displacement limitation, hence, extrapolation of the stress-dilatancy data to the critical state was carried out, based on the technique proposed by Carrera et al. (2011) (Appendix A). Figures 4(a) and 4(b) show the critical states for ballast on $q-p^{\prime}$ and $v$-lnp' plots, and the corresponding BBI at these critical state points are indicated in Fig. 4(c).

The CSL in the $q-p^{\prime}$ plane is non-linear as shown in Fig. 5(a) in comparison with that without breakage set as a Reference Critical State Line (RCSL). RCSL can be approximately determined by drained triaxial compression tests under low confining pressures when particle breakage is insignificant. As expected, the extent of breakage is greater with increasing $p^{\prime}$, 
and the drop in $q$ is more pronounced as $p^{\prime}$ increases. The CSL in $q-p^{\prime}$ plane can be expressed as:

$$
q=\omega \cdot p^{\prime \mu}
$$

where, $\omega$ and $\mu$ are material constants.

The critical state stress ratio $M_{c}=\left(q / p^{\prime}\right)_{c}$ is not a constant for ballast and it is plotted as a function of the confining stress $\sigma_{3}{ }^{\prime}$ and BBI in Fig. 5(b) and 5(c), respectively. The data plotted in Fig. 5 show that the changes in the critical state stress ratio $\left(M_{c}\right)$ with confining stress can be attributed to particle breakage. The particle breakage could be associated with internal work (plastic work) induced by the applied stress. The total plastic work $\left(W_{T}^{P}\right)$ involved in the monotonic shearing process includes two parts: (i) $W_{R}^{P}$ utilised during particle rearrangement, and (ii) $W_{E}^{P}$ accounting for particle breakage (effective plastic work). The critical state stress ratio $\left(M_{c}\right)$ evolves mainly in relation to the increase in effective plastic work $\left(W_{E}^{P}\right)$, which is defined as the excess of total plastic work $\left(W_{T}^{P}\right)$ over the plastic work associated with particle rearrangement $\left(W_{R}^{P}\right)$. Salim and Indraratna (2004) stated that the increment of energy consumption due to particle breakage per unit volume is proportional to the increment of breakage index. The test data in this study showed similar results (i.e. $W_{E}^{P}=\beta \cdot B B I$, where $\beta$ is the constant of proportionality). As particle breakage increases, $M_{c}$ decreases as shown earlier in Fig. 5(c), and can be represented by the following expression:

$$
M_{c}=M_{c 0}-[1-\exp (-\alpha \cdot B B I)]
$$

where, $\alpha$ is model parameter, and $M_{c 0}=$ critical state stress ratio for $\mathrm{BBI}=0$.

The CSL is traditionally written in the $v-\ln p^{\prime}$ plane as: 
where, $\Gamma$ and $\lambda$ are two constitutive parameters which define the local position of the CSL in terms of the specific volume $v_{c}$ and the effective mean stress $p^{\prime}$.

The specific volume and effective mean stress obtained by the tests were plotted earlier in Fig. 4(b). It indicated that the CSL for ballast was no longer a straight line, and that the location of CSL would change in the compression plane with the increase of BBI. The CSL in the $v$ - $\ln p^{\prime}$ plane becomes a critical state surface when the extra dimension of BBI is added (Fig. 6). The CSL, in the form of a dashed line in Fig. 6, corresponding to the current value of BBI, is assumed to have a constant slope. As the effective mean stress increases, the particles will break and BBI will rise. The critical state surface cannot exist for stress levels above a certain limit which will depend on the current value of BBI. The occurrence of breakage does not necessarily place the material in a critical state but changes the critical state to which the material would approach as it is subsequently sheared (Muir Wood and Maeda 2008). Figure 6 shows the three-dimensional nature of this critical state surface.

In this study, it is proposed that the critical state surface in the $v$-ln $p^{\prime}-B B I$ space might be extended from rather traditional $v$-lnp' relationship of eq. [4] by considering:

$$
v_{c}=\Gamma(B B I)-\lambda \ln p^{\prime}
$$

where, $\Gamma(B B I)$ decreases as BBI increases. Based on the drained compression test data, a hyperbolic relation could be derived for $\Gamma(B B I)$ as:

$$
\Gamma(B B I)=\Gamma_{r e f}-a \cdot \exp (b \cdot B B I)
$$

where, $\Gamma_{r e f}$ is the reference value to $\Gamma(B B I), a$ and $b$ are material constants controlling the evolution rate of the CSL with particle breakage. 
The above concept is based on the model of Muir Wood and Maeda (2008) which is supported to some extent by ballast data in this study. In Fig. 6, the plotted data for ballast indicates that with increasing $p^{\prime}$, ballast breakage increases and the corresponding specific volume $(v=1+e)$ decreases, which is in line with the hypothesis of the model suggested by Muir Wood and Maeda (2008). It is true that finer grained materials such as sands may require a ring shear equipment to reach terminal grading (Coop et al. 2004; Sadrekarimi and Olson 2011). Bandini and Coop (2011) used a biogenic carbonate sand with weak particles and found that the movement of CSL was small even for large amounts of breakage. Coarser ballast underwent significant breakage in the large-scale triaxial equipment as shown in Figs. 4 and 6. There is no doubt that the current experimental data for ballast indicates that a downward shift of the CSL is caused by ballast breakage (Fig. 4(b)) although this downward shift may not be as pronounced as predicted by the Muir Wood and Maeda (2008) model.

The state parameter $\psi$ is defined as (Been and Jefferies 1985):

$$
\psi=v-v_{c}
$$

where, $v$ is the current volume, and $v_{c}$ is the critical state volume. Substituting eqs. [5] and [6] into eq. [7] gives,

$$
\psi=v-\Gamma_{r e f}+a \cdot \exp (b \cdot B B I)+\lambda \ln p^{\prime}
$$

Hence, the current state of the sample is linked to the critical state by the introduction of a state parameter. Equation [8] also represents the evolution of $\psi$ as a function of BBI.

\section{Constitutive model for ballast}

The total strain rate is decomposed into elastic and plastic components according to: 
where, the superscripts ' $e$ ' and ' $p$ ' denote the elastic and plastic components, respectively.

\section{Elastic behaviour}

The elastic deviatoric strain increment $d \varepsilon_{s}^{e}$ can be obtained by:

$$
d \varepsilon_{s}^{e}=\frac{d q}{3 G}
$$

where, $G$ is elastic shear modulus.

The elastic volumetric strain increment $d \varepsilon_{v}^{e}$ can be determined by:

[11] $d \varepsilon_{v}^{e}=\frac{3(1-2 v) d p^{\prime}}{2(1+v) G}$

where, $v$ is the Poisson's ratio.

\section{Plastic behaviour and yield function}

Vectors of incremental plastic strain $\left(\delta \varepsilon_{s}^{p}\right.$ and $\left.\delta \varepsilon_{v}^{p}\right)$ obtained from the tests have been plotted along the stress paths in Fig. 7 for constant stress ratios $\eta=q / p^{\prime}$, varying from 0.6 to 1.5 . The plastic strains were derived from the total strains by substracting the elastic strains computed at the corresponding stress increment. Plastic strains are assumed to develop at the start of the deviatoric stress path. Figure 7 indicates that yielding is activated at the initial unloaded state. In the current analysis, the yield surface in $q-p^{\prime}$ plane is described by the simple linear relationship:

$$
f=q / p^{\prime}-\eta_{s}=0
$$


where, $\eta_{s}$ is the hardening law.

The hardening relationship linking the change in location of yield locus (change in stress ratio) to the distortional strain is assumed as:

$$
\eta_{s}=\frac{\varepsilon_{s}^{p}}{B_{m}+\varepsilon_{s}^{p}} M_{p}
$$

where, $B_{m}$ is a material constant linked to the initial stiffness of the ballast, $M_{p}$ is a 'virtual' peak stress ratio attainable at the current state defined by $\psi$. The idea of having a virtual peak stress ratio is to address the issue of peak stress and subsequent softening of specimens under drained conditions. This is similar to the concept proposed by Muir Wood et al. (1994) considering strain softening for sand modelling. In this study, $M_{p}$ is related to the state parameter $\psi$ by the following expression:

$$
M_{p}=M_{c}\left(1-k_{p} \psi\right)
$$

where, $M_{c}$ is critical state stress ratio, and $k_{p}$ is a constant. $M_{p}$ is variable with $\psi$ in a way that yields $M_{p}>M_{c}$ for $\psi<0$ (dense states), $M_{p}<M_{c}$ for $\psi>0$ (loose states), and $M_{p}=M_{c}$ for $\psi=0$ (critical states)

Substituting eqs. [3], [8] and [14] into eq. [13], the hardening function can now be expressed as:

$$
\eta_{s}=\frac{\varepsilon_{s}^{p}}{B_{m}+\varepsilon_{s}^{p}}\left[M_{c 0}-\left(1-e^{-\alpha \cdot B B I}\right)\right] \cdot\left[1-k_{p}\left(v-\Gamma_{r e f}+a \cdot e^{b \cdot B B I}+\lambda \ln p^{\prime}\right)\right]
$$

Equation [15] indicates that the hardening of ballast depends on $\varepsilon_{s}^{p}, \psi$ and BBI.

\section{Dilatancy for ballast}


Figure 8 shows that for two specimens of the same bulk unit weight (i.e. $\gamma_{b}=15.3 \mathrm{kN} / \mathrm{m}^{3}$ ), the ballast specimen initially contracts then dilates under low confining pressure (i.e. $\sigma_{3}{ }^{\prime}=30$ $\mathrm{kPa}$ ), while it undergoes compression when the confining pressure is considerably higher (i.e. $\sigma_{3}{ }^{\prime}=360 \mathrm{kPa}$ ). Furthermore, considering ballast specimens with different bulk unit weights (i.e. $\gamma_{b}=15.3 \mathrm{kN} / \mathrm{m}^{3}$ and $11.2 \mathrm{kN} / \mathrm{m}^{3}$ separately) subjected to a shear loading increment for the same $\eta$ (i.e. $\sigma_{3}{ }^{\prime}=60 \mathrm{kPa}$ ), the dilation response of the two specimens is different as shown in Fig. 8. Both specimens translates from compression to dilation, however, the transformation point for the looser specimen $\left(\gamma_{b}=11.2 \mathrm{kN} / \mathrm{m}^{3}\right)$ is at a higher deviatoric strain compared to the denser one $\left(\gamma_{b}=15.3 \mathrm{kN} / \mathrm{m}^{3}\right)$, which confirms the expectation that the looser specimens experience more compression. The separation between the region of compression and the region of dilation for drained tests on ballast occurs at the phase transformation state at which $\eta=M_{d}$ and dilatancy $D=0$, as shown in Fig. 8 .

Based on the aforementioned observations and accounting for the critical state constitutive framework, one may propose the following state dependent dilatancy relationship for ballast:

$$
D=\frac{d \varepsilon_{v}^{p}}{d \varepsilon_{s}^{p}}=A_{d}\left(M_{d}-\eta\right)
$$

where, $M_{d}$ is the phase transformation stress ratio that can be expressed by:

$$
M_{d}=M_{c} \exp \left(k_{d} \psi\right)
$$

In the above equations, $A_{d}$ and $k_{d}$ are two characteristic model parameters.

Substituting eqs. [3], [8] and [17] into eq. [16], the dilatancy term $D$ can be expressed by:

$$
D=A_{d}\left\{\left[M_{c 0}-\left(1-e^{-\alpha \cdot B B I}\right)\right] \cdot e^{k_{d}\left[\nu-\Gamma_{r e f}+a \cdot \exp (b \cdot B B I)+\lambda \ln p^{\prime}\right]}-\eta\right\}
$$


It can be seen that the conventional Cam-clay dilatancy $D=M-\eta$ is a special case of eq. [18] (i.e. $A_{d}=1, k_{d}=0$ and $\mathrm{BBI}=0$ ). Note that at a critical state, $\psi=0$ and $\eta=M_{c}$ simultaneously, eq. [18] yields zero dilation, obeying the traditional critical state theory. It can also be observed from eq. [18] that the dilatancy depends not only on $M_{c 0}$ and $\eta$ but also on $\psi$ as proposed by Manzari and Dafalias (1997) as well as on particle breakage (BBI). At phase transformation points, $D=0$, the corresponding stress ratio $\eta=M_{d}=M_{c} \exp \left(k_{d} \psi\right)$ is obtained. It postulates that $D$ depends on the difference of the current stress ratio $\eta$ from a reference stress ratio $M_{c} \exp \left(k_{d} \psi\right)$. This concept is similar to those described by Manzari and Dafalias (1997) and Li and Dafalias (2000).

The phase transformation state and the critical state are very similar, as discussed by Luong (1982). For loose ballast and ballast at high confining pressure, $D=0$ is reached at the critical state. The critical state is therefore the same as the phase transformation state, and it occurs at failure for ballast that compresses during shear. For dense ballast or ballast at low confining pressure, the phase transformation state is reached at small strain magnitudes, as indicated in Fig. 8, while the critical state is reached at large strains. Hence, the phase transformation state can be used to give an indication of critical state stress ratio $M_{c}$ for the specimens testing with $\sigma_{3}{ }^{\prime}=30,60 \mathrm{kPa}$. The corresponding technique is shown in Appendix A.

\section{Stress-strain relationship}

The incremental elasto-plastic stress-strain relationship is written as:

$$
\delta \sigma^{\prime}=\left(D^{e}-\frac{D^{e} m n^{T} D^{e}}{H+n^{T} D^{e} m}\right) \delta \varepsilon
$$


where $D^{e}$ is the elastic compliance matrix, $n=\left[n_{p}, n_{q}\right]^{T}$ is the unit vector normal to the loading surface at the current stress state $\sigma^{\prime}$, and $m=\left[m_{p}, m_{q}\right]^{T}$ is the unit direction of plastic flow at $\sigma^{\prime}$, and $H$ is the hardening modulus. The derivation of $H$ is given in Appendix B.

\section{Model calibration and validation}

\section{Model calibration}

As summarised in Table 2, there are three particle breakage parameters, ten plastic parameters and two elastic parameters in the proposed model. To assess the values of breakage parameters $\theta_{b}, v_{b}$, and $\omega_{b}$, it is necessary to measure the BBI at various levels of strain. As shown in Fig. 9, these parameters can be determined by replotting the breakage data as $B B I\left(\omega_{b}-\ln p_{i}^{\prime}\right)$ versus $\varepsilon_{s}^{p}$ and finding the coefficients of the nonlinear function represented by eq. [1].

The critical state parameters $\left(M_{c 0}, \Gamma_{r e f}\right.$ and $\left.\lambda\right)$ can be obtained by conducting a series of drained triaxial compression tests at different effective confining pressures and plotting the test data on the $q-p^{\prime}$ and $v$-lnp' planes. The slope of the line connecting the critical states under low confining pressures on the $q-p^{\prime}$ plane gives the value of $M_{c 0}$, and that of the $v-\ln p^{\prime}$ plane gives the value of $\lambda$. The value of $\Gamma_{\text {ref }}$ is the specific volume of the CSL at $p^{\prime}=1 \mathrm{kPa}$ on the $v$-lnp' plane. By plotting the triaxial test results on the $B B I-M_{c}$ plane, the coefficient $\alpha$ can be obtained by applying the least squares method to eq. [3], knowing $M_{c 0}$. Similarly, on the $B B I-\Gamma$ plane, parameters $a$ and $b$ can be obtained by curve fitting eq. [6] once $\Gamma_{r e f}$ is known.

The parameter $k_{d}$ can be determined by eq. [16] at a phase transformation state, at which $D=$ 0. Hence, 
[20] $\quad k_{d}=\frac{1}{\psi_{d}} \ln \frac{M_{d}}{M_{c}}$

where, $\psi_{d}$ and $M_{d}$ are the values of $\psi$ and $\eta$ at the phase transformation state, measured from drained test results.

The parameter $k_{p}$ is determined by eq. [14] at a drained peak stress state, thus,

$$
k_{p}=\frac{1}{\psi_{p}}\left(1-\frac{M_{p}}{M_{c}}\right)
$$

where, $\psi_{p}$ and $M_{p}$ are the values of $\psi$ and $\eta$ at the drained peak stress state, obtained from the laboratory results.

Using eq. [18], the parameter $A_{m}$ is determined from the $\varepsilon_{v}-\varepsilon_{s}$ curves (Fig. 3). Parameter $B_{m}$ is obtained by best-fit regression based on the $q / p^{\prime}-\varepsilon_{s}$ curves and using eq. [13].

Shear modulus $G$ is calibrated from the initial small strain response of the drained triaxial compression tests. This procedure is illustrated in Appendix C. The Poisson's ratio was assumed to be constant (i.e. $v=0.3$ ). Using $G$ and $v$, the elastic strains can be readily computed, while the plastic increments are then obtained by subtracting the elastic component from the total strains.

\section{Model validation}

Independent sets of triaxial test results were used for initial calibration and for subsequent validation of the model. Three types of ballast, three types of rockfill materials giving a total of 23 independent sets of data were adopted (Varadarajan et al. 2003; Chavez and Alonso 2003; Indraratna et al. 1998, 2013; Salim and Indraratna 2004; Suiker et al. 2005; Anderson and Fair 2008; Aursudkij et al. 2009). The parameters used for the model are shown in Table 
2. Figures 10( $\mathrm{a}$ and $\mathrm{b})$ show the stress-strain and volume change predictions of ballast behaviour employing the current model, in comparison with laboratory observations, respectively. The model predictions without any breakage are also shown for comparison. Figure 10(a) indicates that particle breakage decreases the shear strength of ballast. As the confining pressure increases, the reduction in strength is more pronounced with greater particle breakage. Figure 10(b) shows that only a small difference is evident in volumetric strain response between the model prediction with particle breakage and the one without particle breakage for small confining pressure (i.e. $\sigma_{3}{ }^{\prime}=60 \mathrm{kPa}$ ). As shown in Fig. 10(b), particle breakage causes the specimens to be more compressive, and as the confining pressure $\left(\sigma_{3}^{\prime}\right)$ increases this effect is more pronounced. Figure 10(c) shows the model predictions of particle breakage at various values of $\sigma_{3}{ }^{\prime}$, where the BBI values have been obtained at the end of each test. It is evident from Fig. 10(c) that BBI increases with the increasing $\sigma_{3}{ }^{\prime}$ and $\varepsilon_{s}$. The breakage data from Indraratna and Salim (2002) were also used to compare with the model predictions. Good agreement is found between the test data and model predictions. Simulations with and without particle breakage for the variation in void ratio during the shearing are given in Fig. 10(d), which also shows an acceptable agreement with laboratory data.

Drained tests from Indraratna et al. (1998) are shown in Figs. 11(a) and 11(b). The pre-shear void ratios $\left(e_{i}\right)$ for the ballast specimens have been determined from weight-volume relationships and been summarised in Table 2 . The critical state was determined by extrapolation of stress-strain data to a most probable value following an approach recommended by Carrera et al. (2011). The BBI values calculated by eq. [1] were used to calibrate the model. The stress-strain-volume behaviour is well captured for the specimen with $\sigma_{3}{ }^{\prime}=120 \mathrm{kPa}$. For the specimen with lower confining pressure (e.g. $\sigma_{3}{ }^{\prime}=30 \mathrm{kPa}$ ), the proposed model fits well with the experimental results considering volumetric strain even 
though difference between the simulation and the experimental result can be observed for stress-strain behaviour. Figures $11(\mathrm{c}, \mathrm{d}$, e \& f) provide the predictions for drained tests reported by Indraratna et al. (2013) and Salim and Indraratna (2004). The strain softening behaviours of the specimens are well captured.

Comparisons of the observed and computed behaviour of ballast from Suiker et al. (2005) are shown in Figs. 12(a and b). The peak strength and volumetric strains are reasonably well represented by the model. It is thus evident that the analytical formulations of particle breakage and nonlinear critical state envelopes adopted in this study are appropriate. Figures 12(c and d) and 12(e and f) show the comparisons of drained triaxial compression tests from Anderson and Fair (2008) and Aursudkij et al. (2009). The stress-strain-volumetric behaviour is well captured for both the specimens. As the studies by Suiker et al. (2005) and Anderson and Fair (2008) did not present the variation of particle breakage against axial strains, the same breakage parameters for latite basalt have been assumed in the analysis. This assumption did not hinder the accuracy of the model predictions as evident from Figs. 12(a, b, c \& d). This is because, similar igneous parent rock types, namely basalt and granite, have been used by Suiker et al. (2005) and Anderson and Fair (2008), respectively.

The mechanical response of rockfill is largely dominated by particle breakage. The predictions of the stress-strain-volumetric behaviour for three rockfill materials (Varadarajan, et al. 2003; Chavez and Alonso 2003) have been made by using the current model as shown in Figs. 13. The predicted and observed results are very close to each other for the selected materials. As such it may be concluded that the model provides satisfactory prediction of the stress-strain-volumetric change behaviour of the three rockfill materials.

\section{Conclusions}


The current study considers effects of particle breakage and non-linearity of critical state strength envelopes on the monotonic behaviour of ballast. Consolidated drained triaxial tests were conducted using large-scale cylindrical apparatus at various confining pressures. The shearing was continued at relatively large axial strain (maximum 30\%) in order to attain a critical state although in some cases $\left(\sigma_{3}{ }^{\prime}=30,60 \mathrm{kPa}\right)$ an extrapolation was needed. An elasto-plastic state dependent constitutive model based on critical state soil mechanics framework is proposed to address aspects of particle breakage and nonlinear behaviour.

This study has shown that particle breakage can significantly influence the critical state. At relatively higher confining pressure $\left(\sigma_{3}{ }^{\prime} \geq 180 \mathrm{kPa}\right)$, particle breakage is more pronounced and this causes a shift of the location of critical state line on the $q-p^{\prime}$ and $v$-lnp' planes. As particle breakage increases, the critical state stress ratio $M_{c}$ decreases. The CSL on $v$-lnp' plane is no longer a straight line, and the location of CSL changes as the extent of breakage (BBI) increases. The CSL on the $v$-lnp' plane becomes a critical state surface when the extra dimension of $\mathrm{BBI}$ is added. Based on the drained compression test data, a hyperbolic relation for the critical state surface was proposed to relate the specific volume with BBI.

During triaxial shearing, the hardening of ballast depends on $\varepsilon_{s}^{p}, \psi$ and $\mathrm{BBI}$ and this can be reflected by a hyperbolic hardening relationship. Dilatancy for ballast depends not only on $\eta$, and $\psi$ but also on BBI. The present study reveals that effects of particle breakage and their implications on the nonlinearity of CSL are successfully captured in the constitutive equations, and the model predictions are encouraging when compared with the laboratory data. 


\section{Acknowledgements}

This work has been financially supported by the China Scholarship Council: this support is gratefully acknowledged. We would like to thank Alan Grant and Rick McLean at University of Wollongong for their assistance in the laboratory.

\section{References}

Anderson, W. F., and Fair, P. 2008. Behaviour of railroad ballast under monotonic and cyclic loading. Journal of Geotechnical and Geoenvironmental Engineering, ASCE, 134(3): 316-327.

Aursudkij, B., McDowell, G. B., Collop, A. C. 2009. Cyclic loading of railway ballast under triaxial conditions and in a railway test facility. Granular Matter, 11(6): 391-401.

Bandini, V. and Coop, M. R. 2011. The influence of particle breakage on the location of the critical state line of sands. Soil and Foundations. 51(4): 591-600.

Bedin, J., Schnaid, F., Da Fonseca, A. V. and De M. Coasta Filho, L. 2012. Gold tailings liquefaction under critical state soil mechanics. Géotechnique, 62(3): 263-267. 
Been, K., and Jefferies, M. G. 1985. A state parameter for sands. Géotechnique, 35(2): 99112.

Been, K., Jefferies, M. G., and Hachey, J. 1991. The critical state of sands. Géotechnique, 41(3): 365-381.

Carrera, A., Coop, M. R. and Lancellotta, R. 2011. The Influence of grading on the mechanical behaviour of Stava tailings. Géotechnique, 61(11): 935-946.

Charles, J. A. and Watts, K. S. 1980. The influence of confining pressure on the shear strength of compacted rockfill. Géotechnique, 30(4): 353-367.

Chavez, C., and Alonso, E. F. 2003. A constitutive model for crushed granular aggregates which includes suction effects. Soils and Foundations, 43(4): 215-227.

Cheng, Y. P., Bolton, M. D. and Nakata, Y. 2005. Grain crushing and critical states observed in DEM simulations. Powers and Grains 2005-Proceedings of the 5th International Conference on Micromechanics of Granular Media, 2: 1393-1397.

Coop, M. R. 1990. The mechanics of uncemented carbonate sands. Géotechnique, 40(4): 607626.

Coop, M. R., Sorensen, K. K., Bodas Freitas, T., and Georgoutsos, G. 2004. Particle breakage during shearing of a carbonate sand. Géotechnique, 54(3): 157-163.

Daouadji, A., Hicher, P. Y., and Rahma, A. 2001. An elastoplastic model for granular materials taking into account grain breakage. European Journal of Mechanics ASolids, 20(1): 113-137.

Henkel, D. J. and Gilbert, G. D. 1952. The effect of the rubber membrane on the measured triaxial compression strength of clay samples. Géotechnique, 3(1): 20-29.

Indraratna, B., and Salim, W. 2002. Modelling of particle breakage of coarse aggregates incorporating strength and dilatancy. Proceedings of Institute of Civil Engineers, London, 155(4): 243-252. 
Indraratna, B., Ionescu, D., and Christie, H. D. 1998. Shear behaviour of railway ballast on large-scale triaxial tests. Journal of Geotechnical and Geoenvironmental Engineering, ASCE, 124(5): 439-449.

Indraratna, B., Lackenby, J., and Christie, D. 2005. Effect of confining pressure on the degradation of ballast under cyclic loading. Géotechnique, 55(4): 325-328.

Indraratna, B. and Nimbalkar, S. 2013. Stress-strain degradation response of railway ballast stabilized with geosynthetics. Journal of Geotechnical and Geoenvironmental Engineering, 139(5): 684-700.

Indraratna, B., Nimbalkar, S., Coop, M. and Sloan, S. W. 2014. A constitutive model for coal-fouled ballast capturing the effects of particle degradation. Computers \& Geotechnics (accepted, in press).

Indraratna, B., Salim, W., and Rujikiatkamjorn, C. 2011. Advanced Rail GeotechnologyBallasted Track. CRC Press.

Indraratna, B., Tennakoon, N., Nimbalker, S., and Rujikiatkamjorn, C. 2013. Behaviour of clay-fouled ballast under drained triaxial testing. Géotechnique, 63(5): 410-419.

Lackenby, J. 2006. Triaxial behaviour of ballast and the role of confining pressure under cyclic loading. $\mathrm{PhD}$ thesis, Department of Civil Engineering, University of Wollongong, NSW, Australia.

Lackenby, J., Indraratna, B., McDowell, G., and Christie, D. 2007. Effect of confining pressure on ballast degradation and deformation under cyclic triaxial loading. Géotechnique, 57(6), 527-536.

Lade, P.V., Yamamuro, J. A., and Bopp, P. A. 1996. Significance of particle crushing in granular materials. Journal of Geotechnical Engineering, ASCE, 122(4): 309-316.

Lee, K. L. and Farhoomand, I. 1967. Compressibility and crushing of granular soil in anisotropic triaxial compression. Canadian Geotechnical Journal, 4(1): 69-86. 
Li, X. S., and Dafalias, Y. F. 2000. Dilatancy for cohesionless soils. Géotechnique, 50(4): $449-460$.

Luong, M. P. 1982. Stress-strain aspects of cohesionless soils under cyclic and transient loading. International Symposium on Soil under Cyclic and Transient Loading, A. A Balkema, Rotterdam, 315-324.

Manzari, M. T., and Dafalias, Y. F. 1997. A critical state two-surface plasticity model for sands. Géotechnique, 47(2): 255-272.

Marachi, N. D., Chan, C. K. and Seed, H. B. 1972. Evaluation of properties of rockfill materials. Journal of the Soil Mechanics and Foundations Division, ASCE, 98(1): 95114.

Marsal, R. J. 1967. Large-scale testing of rockfill materials. Journal of the Soil Mechanics and Foundations Division, ASCE, 93(2): 27-43.

McDowell, G. R. and Bolton, M. D. 1998. On the micromechanics of crushable aggregates. Géotechnique, 48(5): 667-679.

Mooney, M. A., Finno, R. J., and Viggiani, M. G. 1998. A unique critical state for sand?. Journal of Geotechnical and Geoenvironmental Engineering ASCE, 124(11), 11001108.

Muir Wood, D., Belkheir, K., and Liu, D. F. 1994. Strain softening and state parameter for sand modelling. Géotechnique, 44(2): 335-339.

Muir Wood. D., and Maeda, K. 2008. Changing grading of soil: effect on critical states. Acta Geotechnica, 3(1): 3-14.

Nimbalkar, S., Indraratna, B., Dash, S. K., and Christie, D. 2012. Improved performance of railway ballast under impact loads using shock mats. Journal of Geotechnical and Geoenvironmental Engineering, ASCE, 138(3), 281-294. 
Russell, A. R., and Khalili, N. 2004. A bounding surface plasticity model for sands exhibiting particle crushing. Canadian Geotechnical Journal, 41(6): 1179-1192.

Sadrekarimi, A., and Olson, S. M. 2011. Critical state friction angle of sands. Géotechnique, 61(9), 771-783.

Salim, W., and Indraratna, B. 2004. A new elastoplastic constitutive model for coarse granular aggregates incorporating particle breakage. Canadian Geotechnical Journal, 41(4): 657-671.

Standards Australia. 1996. Aggregates and rock for engineering purposes. Australia Standard AS 2758.7-1996. Standards Australia, Sydney.

Suiker, A. S. J., Selig, E. T., and Frenkel, R. 2005. Static and cyclic triaxial testing of ballast and subballast. Journal of Geotechnical and Geoenvironmental Engineering, ASCE, 131(6): 771-782.

Ueng, T. S., and Chen, T. J. 2000. Energy aspects of particle breakage in drained shear of sands. Géotechnique, 50(1), 65-72.

Varadarajan, A., Sharma, K. G., Venkatachalam, K., and Gupta, A. K. 2003. Testing and modeling two rockfill materials. Journal of Geotechnical and Geoenvironmental Engineering, ASCE, 129(3): 206-218. 


\section{Notation}

$\begin{array}{ll}A_{d} & \text { multiplier in flow rule } \\ a, b & \text { model parameter linking particle breakage to the specific volume } \\ B & \text { Skempton's coefficient } \\ B_{m} & \text { parameter controlling hyperbolic stiffness relationship } \\ \text { BBI } & \text { Ballast Breakage Index } \\ D & \text { dilatancy } \\ e, e_{i} & \text { void ratio and pre-shear void ratio } \\ G & \text { shear modulus } \\ H & \text { hardening modulus } \\ k_{d}, k_{p} & \text { model parameters }\end{array}$




\begin{tabular}{|c|c|}
\hline$M_{c}, M_{c 0}$ & critical state stress ratio with breakage and without breakage, respectively \\
\hline$M_{d}$ & phase transformation state stress ratio \\
\hline$M_{p}$ & peak stress ratio \\
\hline$m, n$ & unit vector along plastic flow and normal to loading surface, respectively \\
\hline$p^{\prime}, p_{i}^{\prime}$ & effective mean stress and initial $p^{\prime}$ \\
\hline$q$ & deviatoric stress \\
\hline$W_{E}^{P}, W_{R}^{P}, W_{T}^{P}$ & effective, used for particle rearrangement and total plastic work \\
\hline$\alpha, \beta$ & model parameters to cater effect of particle breakage \\
\hline$\gamma_{b}$ & bulk unit weight \\
\hline$d \varepsilon_{s}^{e}, d \varepsilon_{v}^{e}$ & elastic deviatoric and volumetric strain increment \\
\hline$\delta \varepsilon^{e}, \delta \varepsilon^{p}$ & elastic and plastic strain increment \\
\hline$\delta \varepsilon_{s}^{p}, \delta \varepsilon_{v}^{p}$ & plastic deviatoric and volumetric strain increment \\
\hline$\varepsilon_{s}, \varepsilon_{v}$ & deviatoric and volumetric strain \\
\hline$\varepsilon_{s}^{p}$ & plastic deviatoric strain \\
\hline$\eta$ & stress ratio $\left(\eta=q / p^{\prime}\right)$ \\
\hline$\eta_{s}$ & hardening law \\
\hline$\theta_{b}$ & particle breakage parameter \\
\hline$\lambda$ & slope of CSL on $v$-lnp' plane \\
\hline$\mu$ & non-linear CSL parameter on $q-p^{\prime}$ plane \\
\hline$v$ & Poisson's ratio \\
\hline$v_{b}$ & particle breakage parameter \\
\hline$\sigma_{3}{ }^{\prime}$ & confining pressure \\
\hline$\Gamma, \Gamma_{r e f}$ & specific volume on the CSL and RCSL at $p^{\prime}=1 \mathrm{kPa}$ \\
\hline$v, v_{c}$ & specific volume and critical state volume \\
\hline$\psi$ & state parameter \\
\hline$\omega$ & non-linear CSL parameter on $q-p^{\prime}$ plane \\
\hline$\omega_{b}$ & particle breakage parameter \\
\hline
\end{tabular}




\section{Figure captions:}

Fig. 1. Ballast breakage index (BBI) calculation method (after Indraratna et al. 2005).

Fig. 2. Particle size distribution of tested ballast, including the upper and lower bounds from Standards Australia (1996).

Fig. 3. Static response of ballast: (a) variation of deviatoric stress $q$ with deviatoric strain $\varepsilon_{s}$ and (b) variation of volumetric strain $\varepsilon_{v}$ with deviatoric strain $\varepsilon_{s}$.

Fig. 4. Monotonic triaxial tests on ballast: (a) ctitical state points on $q-p^{\prime}$ plane, (b) critical state points on $v$-lnp' plane and (c) shift of PSD after triaxial shearing.

Fig. 5. Critical states for ballast: (a) critical state line on $q$ - $p$ ' plane, (b) variation of $M_{c}$ with $\sigma_{3}{ }^{\prime}$ and (c) evolution of $M_{c}$ with BBI. 
Fig. 6. Critical state surface in compression-breakage space (modified after Muir Wood and Maeda 2008).

Fig. 7. Incremental plastic strain vectors along stress paths.

Fig. 8. Variation in dilatancy with material state.

Fig. 9. Particle breakage parameters (data sourced from Indraratna and Salim 2002).

Fig. 10. Model predictions compared with experimental results of drained triaxial shearing:

(a) stress-strain response, (b) volume change behaviour, (c) particle breakage predictions and (d) void ratio.

Fig. 11. Model predictions compared with experimental results of drained triaxial shearing (data sourced from Indraratna et al. 1998, 2013; Salim and Indraratna 2004).

Fig. 12. Model predictions compared with experimental results of drained triaxial shearing (data sourced from Suiker et al. 2005; Anderson and Fair 2008; Aursudkij et al. 2009).

Fig. 13. Model predictions compared with experimental results of drained triaxial shearing for rockfill materials (data sourced from Varadarajan et al. 2003; Chavez and Alonso 2003).

Fig. A1. (a) An example of test $\left(\sigma_{3}{ }^{\prime}=60 \mathrm{kPa}\right)$ that ended before reaching the critical state; (b) estimation of the critical state stress ratio by means of stress-dilatancy based approach.

Fig. C1. Determination of shear modulus $G$. 
Table 1. Summary of the monotonic triaxial tests.

\begin{tabular}{ccc}
\hline Test name & Confining pressure, $\sigma_{3}{ }^{\prime}(\mathrm{kPa})$ & Bulk unit weight, $\gamma_{b}\left(\mathrm{kN} / \mathrm{m}^{3}\right)$ \\
S1 & 30 & 15.3 \\
S2 & 60 & 15.3 \\
S3 & 180 & 15.3 \\
S4 & 240 & 15.3 \\
S5 & 300 & 15.3 \\
S6 & 360 & 15.3 \\
S7 & 420 & 15.3 \\
S8 & 570 & 15.3 \\
S9 & 60 & 11.6 \\
\hline
\end{tabular}


Table 2. Model parameters.

\begin{tabular}{|c|c|c|c|c|c|c|c|c|c|c|c|c|}
\hline \multirow{2}{*}{$\begin{array}{l}\text { Model } \\
\text { properties }\end{array}$} & \multirow[t]{2}{*}{ Parameters } & \multicolumn{2}{|c|}{ Current study } & \multirow{2}{*}{$\begin{array}{l}\text { Indraratna } \\
\text { et al. } \\
\text { (1998) }\end{array}$} & \multirow{2}{*}{$\begin{array}{l}\text { Indraratna } \\
\text { et al. } \\
\text { (2013) }\end{array}$} & \multirow{2}{*}{$\begin{array}{l}\text { Salim and } \\
\text { Indraratna (2004) }\end{array}$} & \multirow{2}{*}{$\begin{array}{l}\text { Suiker et al. } \\
(2005)\end{array}$} & \multirow{2}{*}{$\begin{array}{l}\text { Anderson } \\
\text { and Fair } \\
\text { (2008) }\end{array}$} & \multirow{2}{*}{$\begin{array}{l}\text { Aursudkij et al. } \\
\text { (2009) }\end{array}$} & \multirow{2}{*}{$\begin{array}{l}\text { Varadarajan } \\
\text { et al. }(2003)\end{array}$} & \multirow{2}{*}{$\begin{array}{l}\text { Varadarajan } \\
\text { et al. (2003) }\end{array}$} & \multirow{2}{*}{$\begin{array}{l}\text { Chavez and } \\
\text { Alonso } \\
(2003)\end{array}$} \\
\hline & & $\begin{array}{l}\text { With } \\
\text { breakage }\end{array}$ & $\begin{array}{l}\text { Without } \\
\text { breakage }\end{array}$ & & & & & & & & & \\
\hline Material type & ------ & Basalt & & Basalt & Basalt & Basalt & Basalt & Granite & Limestone & $\begin{array}{l}\text { Sedimentary } \\
\text { rock }\end{array}$ & $\begin{array}{l}\text { Metamorphic } \\
\text { rock }\end{array}$ & $\begin{array}{l}\text { Cambric } \\
\text { slate }\end{array}$ \\
\hline Test details & $\begin{array}{l}\sigma_{3}^{\prime}(\mathrm{kPa}) \\
e_{i}\end{array}$ & $\begin{array}{l}60 / 180 \\
0.732 / 0.75\end{array}$ & & $\begin{array}{l}30 / 120 \\
0.79 / 0.70\end{array}$ & $\begin{array}{l}30 / 60 \\
0.78 / 0.75\end{array}$ & $\begin{array}{l}100 / 200 / 300 \\
0.685 / 0.658 / 0.646\end{array}$ & $\begin{array}{l}10.3 / 41.3 / 68.9 \\
0.53 / 0.70 / 0.70\end{array}$ & $\begin{array}{l}40 / 140 \\
0.84 / 0.82\end{array}$ & $\begin{array}{l}10 / 30 / 60 \\
0.63 / 0.63 / 0.63\end{array}$ & $\begin{array}{l}350 / 700 \\
0.6 / 0.6\end{array}$ & $\begin{array}{l}600 / 900 \\
0.6 / 0.6\end{array}$ & $\begin{array}{l}100 / 300 \\
0.599 / 0.594\end{array}$ \\
\hline $\begin{array}{l}\text { Gradation } \\
\text { characteristics }\end{array}$ & $\begin{array}{l}d_{50}(\mathrm{~mm}) \\
C_{u}\end{array}$ & $\begin{array}{l}39.5 \\
1.53\end{array}$ & & $\begin{array}{l}38.9 \\
1.50\end{array}$ & $\begin{array}{l}38.8 \\
1.55\end{array}$ & $\begin{array}{l}35 \\
1.60\end{array}$ & $\begin{array}{l}24.2 \\
1.70\end{array}$ & $\begin{array}{l}40.4 \\
1.40\end{array}$ & $\begin{array}{l}40 \\
1.56\end{array}$ & $\begin{array}{l}12 \\
95\end{array}$ & $\begin{array}{l}13 \\
13\end{array}$ & $\begin{array}{l}22 \\
2.9\end{array}$ \\
\hline Elasticity & $\begin{array}{l}G(\mathrm{MPa}) \\
v\end{array}$ & $\begin{array}{l}8 / 12 \\
0.3\end{array}$ & & $\begin{array}{l}5.27 / 10.83 \\
0.25\end{array}$ & $\begin{array}{l}5.33 / 7.33 \\
0.25\end{array}$ & $\begin{array}{l}9.33 / 7.83 / 14.67 \\
0.3\end{array}$ & $\begin{array}{l}4.17 / 26.67 / 44.67 \\
0.10\end{array}$ & $\begin{array}{l}23.9 / 35.2 \\
0.25\end{array}$ & $\begin{array}{l}3.67 / 4.17 / 16.67 \\
0.3\end{array}$ & $\begin{array}{l}18.75 / 31.25 \\
0.29\end{array}$ & $\begin{array}{l}33.3 / 33.3 \\
0.31\end{array}$ & $\begin{array}{l}4.67 / 13.33 \\
0.29\end{array}$ \\
\hline $\begin{array}{l}\text { Particle } \\
\text { breakage }\end{array}$ & $\begin{array}{l}\theta_{b} \\
v_{b} \\
\omega_{b}\end{array}$ & $\begin{array}{l}0.33 \\
11.5 \\
6.4\end{array}$ & $\begin{array}{l}0 \\
0 \\
0\end{array}$ & $\begin{array}{l}0.30 \\
11.2 \\
6.1\end{array}$ & $\begin{array}{l}0.31 \\
11.4 \\
6.2\end{array}$ & $\begin{array}{l}0.33 \\
11.5 \\
6.4\end{array}$ & $\begin{array}{l}0.31 \\
11 \\
6.5\end{array}$ & $\begin{array}{l}0.35 \\
12.5 \\
6.8\end{array}$ & $\begin{array}{l}0.01 \\
12 \\
5\end{array}$ & $\begin{array}{l}0.25 \\
15 \\
7.38\end{array}$ & $\begin{array}{l}0.21 \\
12 \\
7.3\end{array}$ & $\begin{array}{l}0.5 \\
13 \\
6.9\end{array}$ \\
\hline Critical state & $\begin{array}{l}\Gamma_{\text {ref }} \\
\lambda \\
M_{c 0} \\
\alpha \\
a \\
b\end{array}$ & $\begin{array}{l}2.41 \\
0.105 \\
2.6 \\
4.287 \\
0.2 \\
1.87\end{array}$ & $\begin{array}{l}2.41 \\
0.105 \\
2.18 / 2.0 \\
0 \\
0 \\
0\end{array}$ & $\begin{array}{l}2.80 \\
0.164 \\
2.52 \\
2.833 \\
0.061 \\
2.267\end{array}$ & $\begin{array}{l}.70 \\
0.123 \\
2.45 \\
4.517 \\
0.048 \\
2.716\end{array}$ & $\begin{array}{l}2.70 \\
0.155 \\
2.24 \\
0.938 \\
0.038 \\
1.127\end{array}$ & $\begin{array}{l}2.30 \\
0.053 \\
2.15 \\
4.424 \\
0.030 \\
12.36\end{array}$ & $\begin{array}{l}2.60 \\
0.112 \\
2.43 \\
6.229 \\
0.016 \\
7.937\end{array}$ & $\begin{array}{l}1.85 \\
0.016 \\
2.4 \\
54.6 \\
0.042 \\
0.8\end{array}$ & $\begin{array}{l}1.65 \\
0.004 \\
2.36 \\
0.748 \\
0.036 \\
1.844\end{array}$ & $\begin{array}{l}1.701 \\
0.009 \\
1.9 \\
1.319 \\
0.025 \\
0.518\end{array}$ & $\begin{array}{l}2.8 \\
0.131 \\
2.426 \\
2.665 \\
0.076 \\
1.868\end{array}$ \\
\hline Dilatancy & $\begin{array}{l}A_{d} \\
k_{d}\end{array}$ & $\begin{array}{l}0.80 \\
1.6\end{array}$ & $\begin{array}{l}1.25 \\
0.8\end{array}$ & $\begin{array}{l}1.40 \\
1.28\end{array}$ & $\begin{array}{l}0.90 \\
0.24\end{array}$ & $\begin{array}{l}0.95 \\
1.20\end{array}$ & $\begin{array}{l}1.60 \\
1.48\end{array}$ & $\begin{array}{l}0.80 \\
2.75\end{array}$ & $\begin{array}{l}0.5 \\
8\end{array}$ & $\begin{array}{l}0.37 \\
13\end{array}$ & $\begin{array}{l}1.05 \\
8\end{array}$ & $\begin{array}{l}1.3 \\
1.2\end{array}$ \\
\hline Hardening & $\begin{array}{l}k_{p} \\
B_{m}\end{array}$ & $\begin{array}{l}1.05 \\
0.017\end{array}$ & $\begin{array}{l}0.8 \\
0.009\end{array}$ & $\begin{array}{l}0.90 \\
0.017\end{array}$ & $\begin{array}{l}0.60 \\
0.009\end{array}$ & $\begin{array}{l}1.20 \\
0.016\end{array}$ & $\begin{array}{l}0.01 \\
0.002\end{array}$ & $\begin{array}{l}0.05 \\
0.003\end{array}$ & $\begin{array}{l}0.4 \\
0.006\end{array}$ & $\begin{array}{l}0.50 \\
0.0088\end{array}$ & $\begin{array}{l}0.2 \\
0.009\end{array}$ & $\begin{array}{l}0.25 \\
0.026\end{array}$ \\
\hline
\end{tabular}




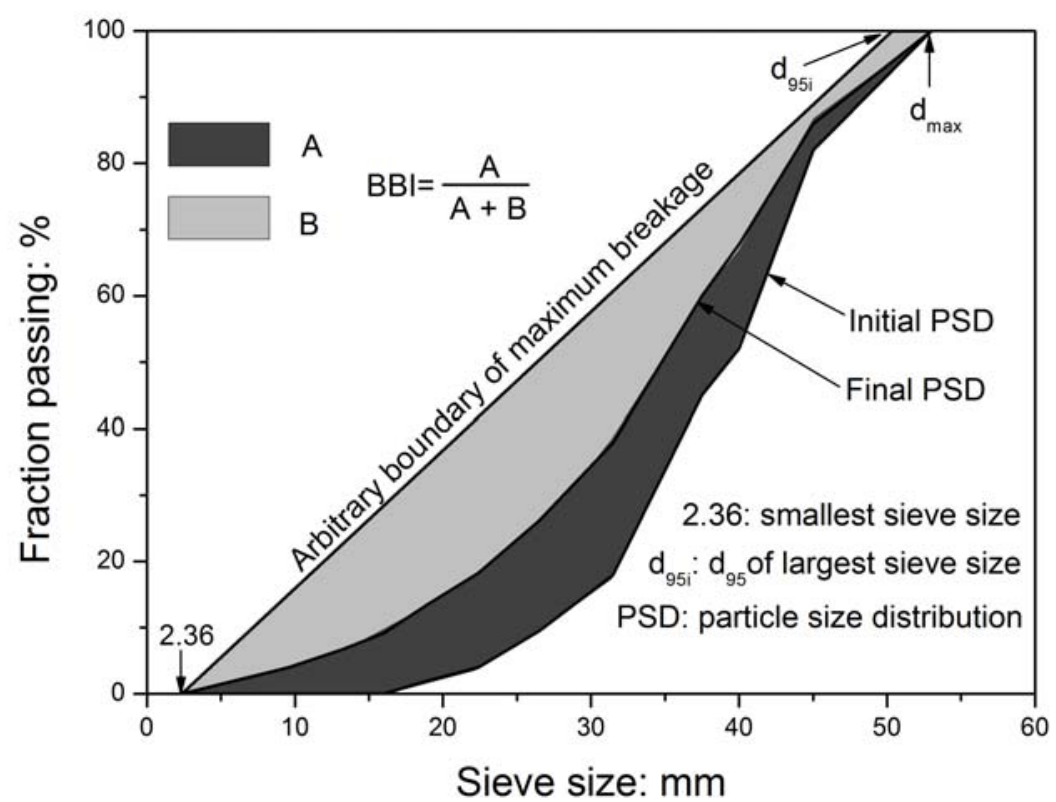

Fig. 1. Ballast breakage index (BBI) calculation method (after Indraratna et al. 2005). 


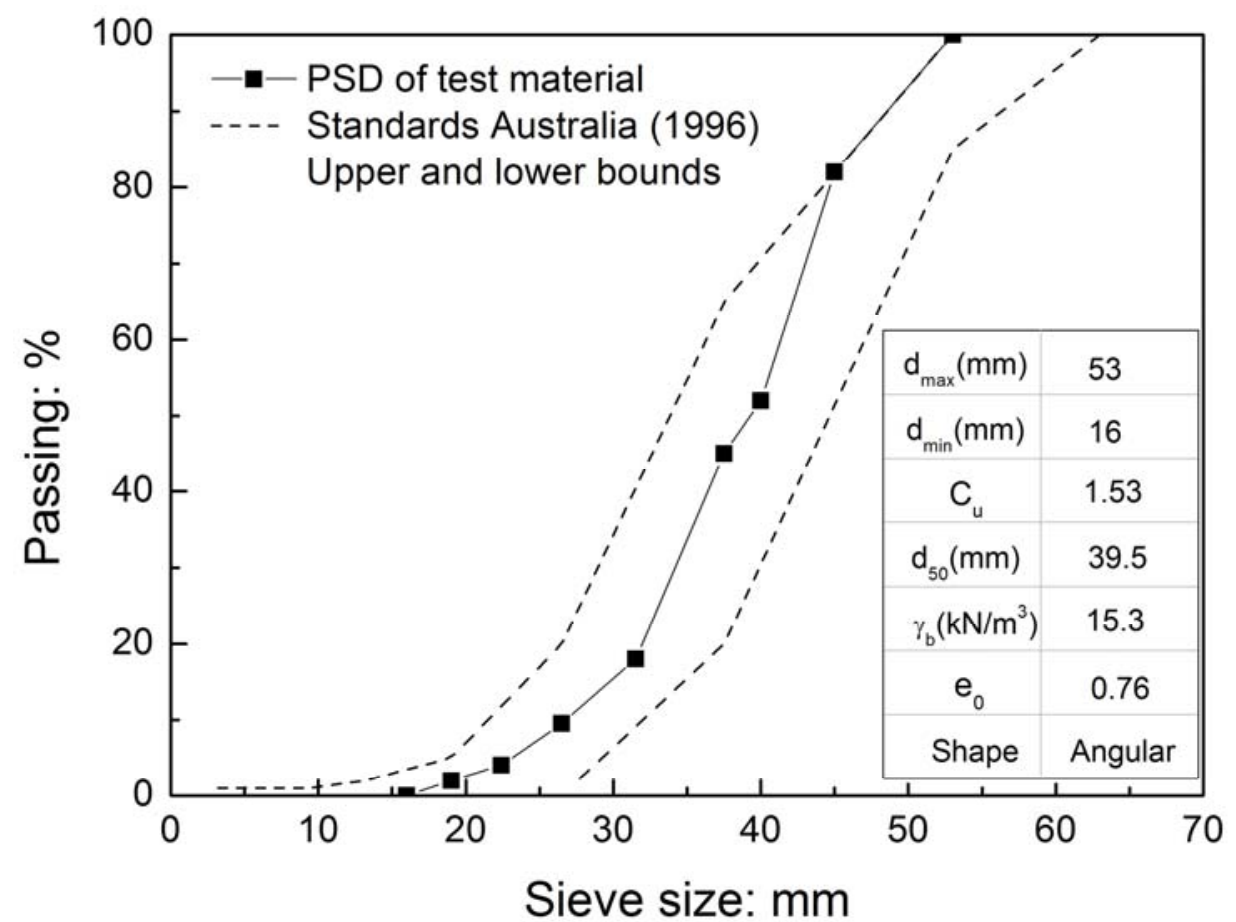

Fig. 2. Particle size distribution of tested ballast, including the upper and lower bounds from Standards Australia (1996). 


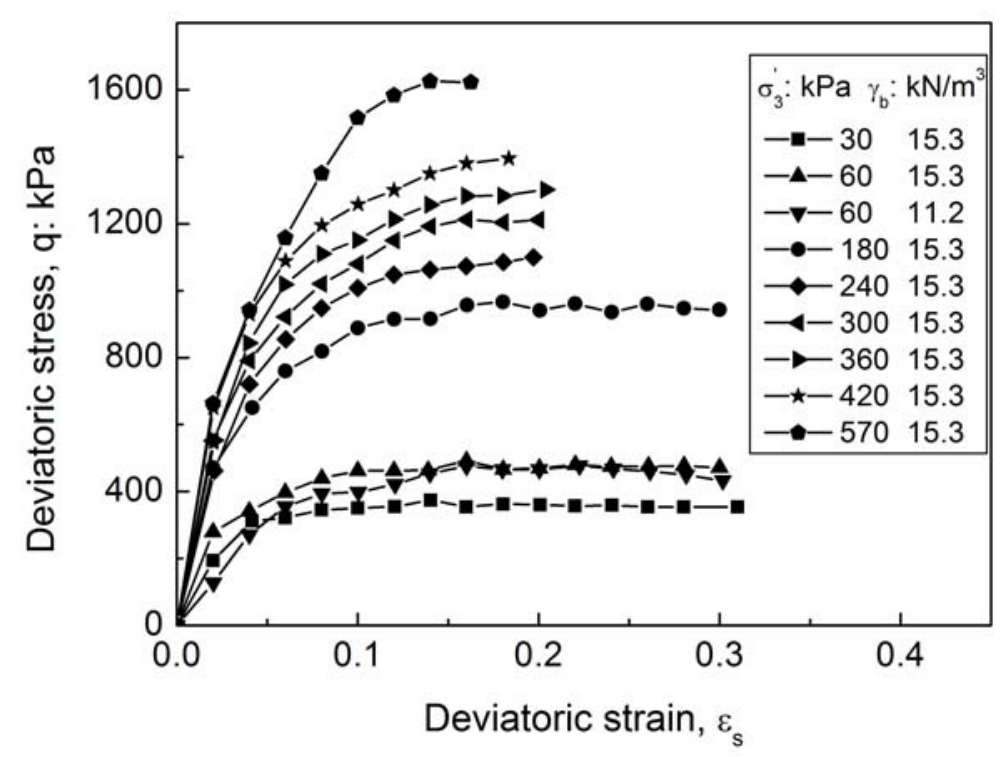

(a)

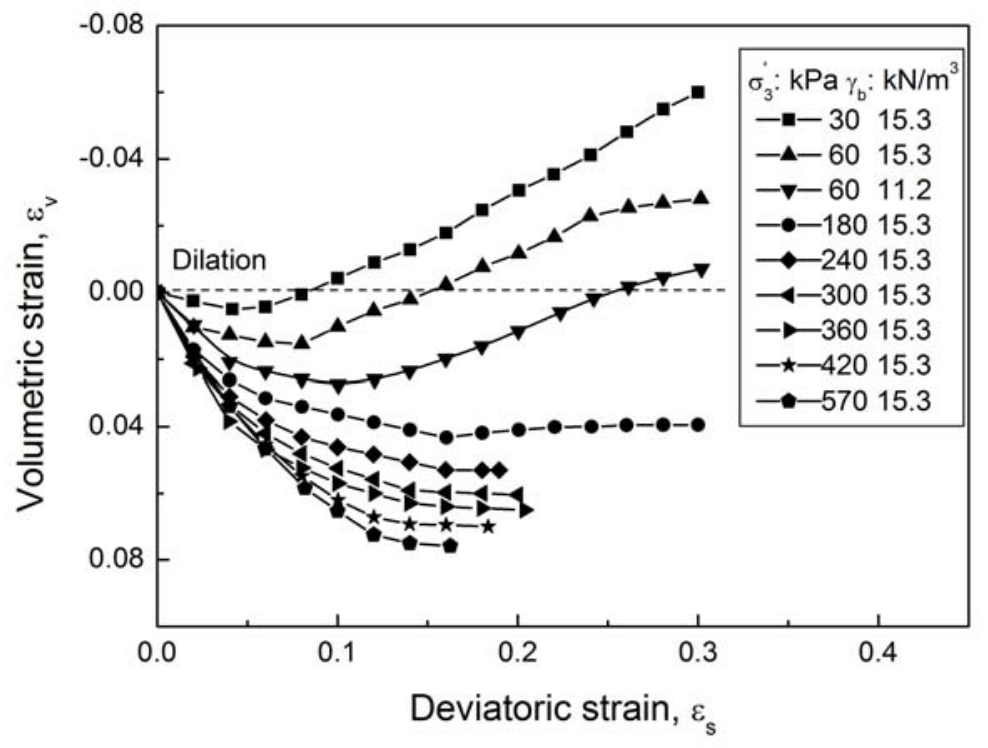

(b)

Fig. 3. Static response of ballast: (a) variation of deviatoric stress $q$ with deviatoric strain $\varepsilon_{s}$ and (b) variation of volumetric strain $\varepsilon_{v}$ with deviatoric strain $\varepsilon_{s}$. 


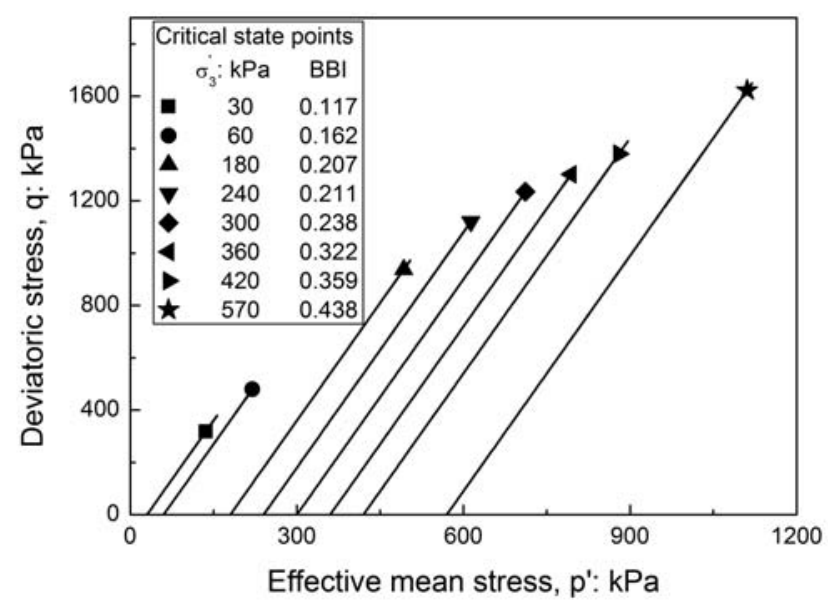

(a)

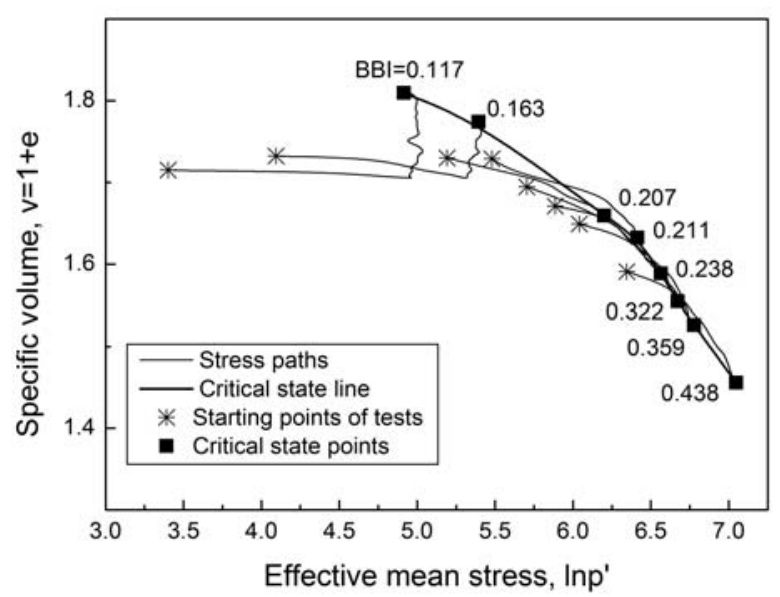

(b)

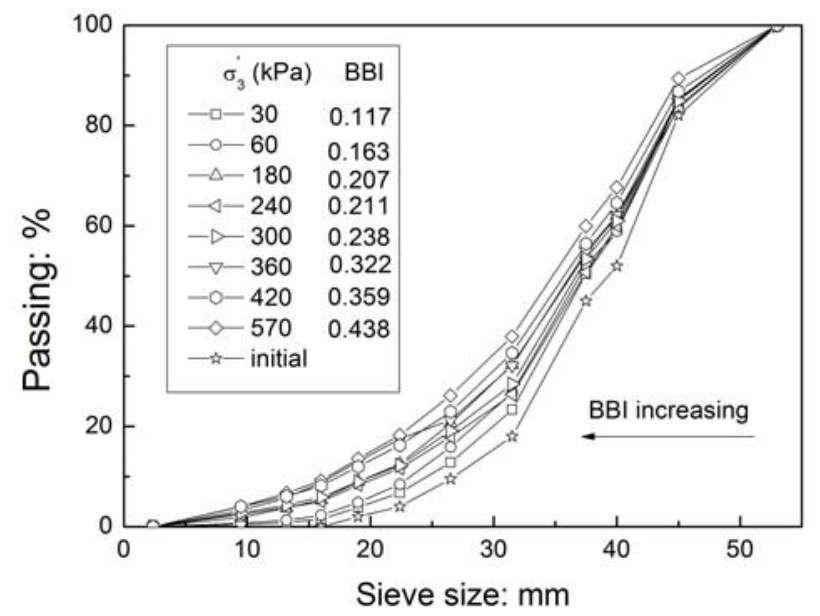

(c)

Fig. 4. Monotonic triaxial tests on ballast: (a) ctitical state points on $q-p^{\prime}$ plane, (b) critical state points on $v$-lnp' plane and (c) shift of PSD after triaxial shearing. 


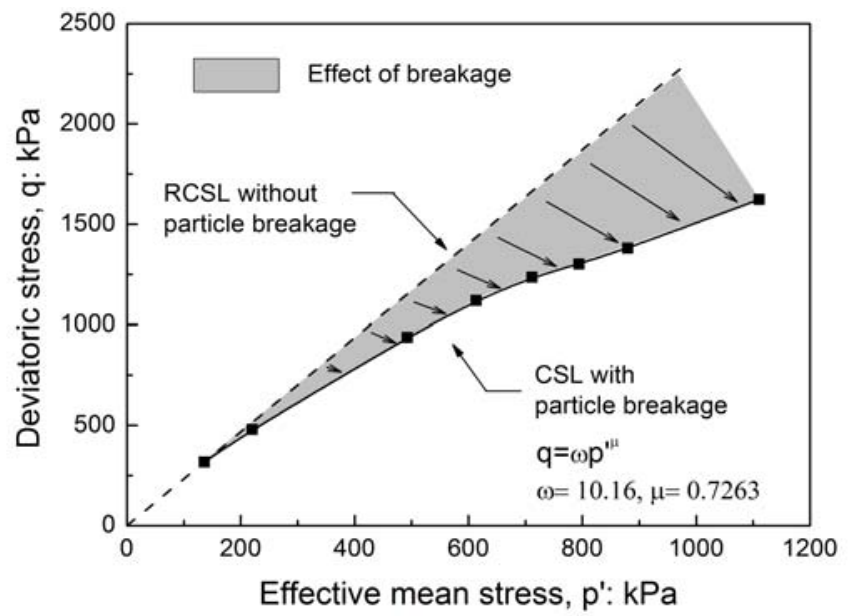

(a)

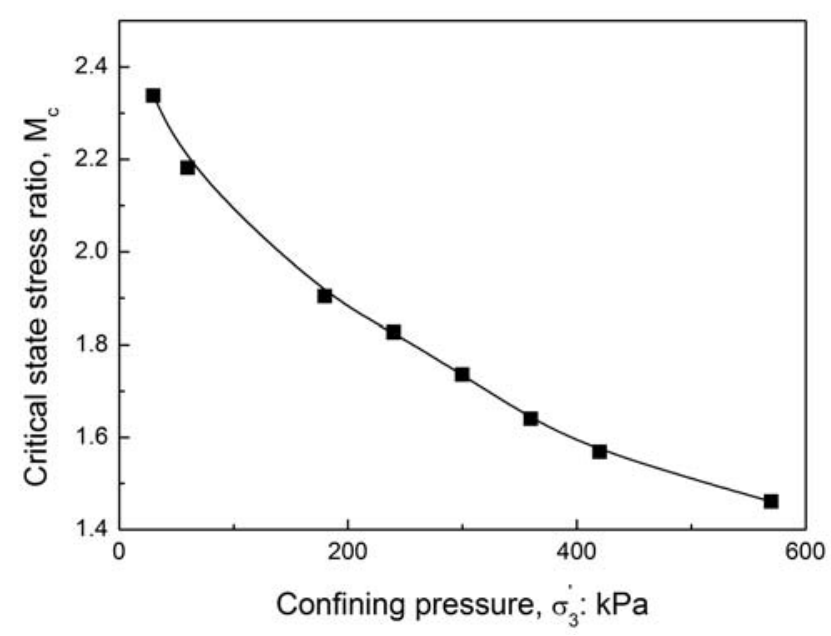

(b)

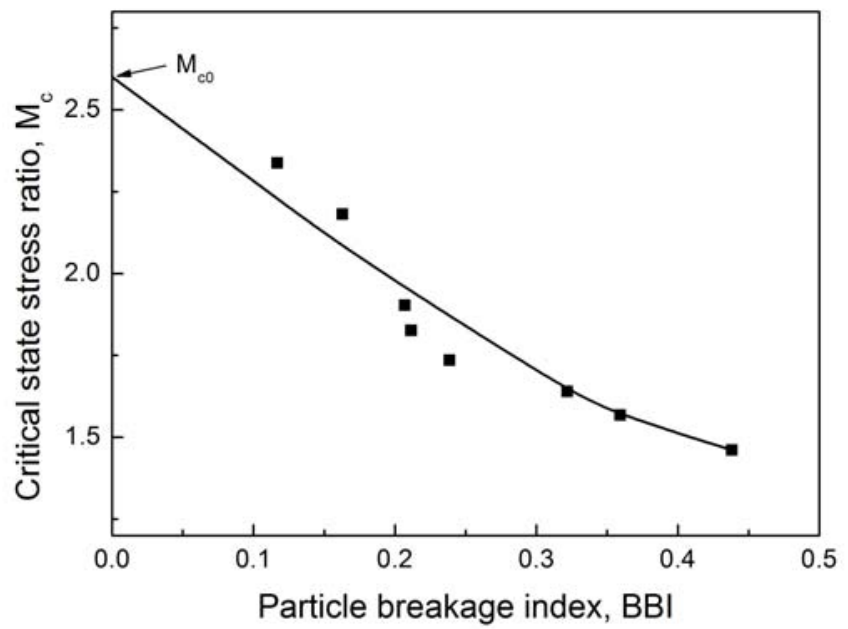

(c)

Fig. 5. Critical states for ballast: (a) critical state line on $q-p^{\prime}$ plane, (b) variation of $M_{c}$ with $\sigma_{3}{ }^{\prime}$ and (c) evolution of $M_{c}$ with BBI. 


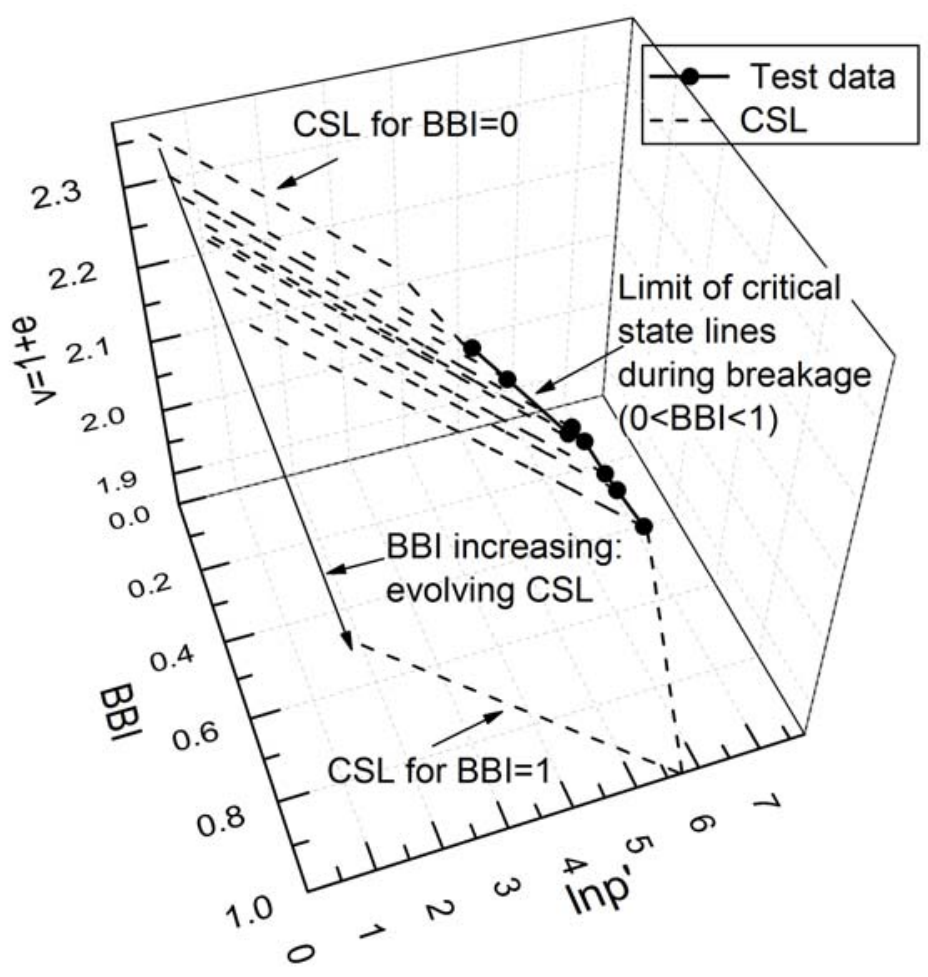

Fig. 6. Critical state surface in compression-breakage space (modified after Muir Wood and Maeda 2008). 


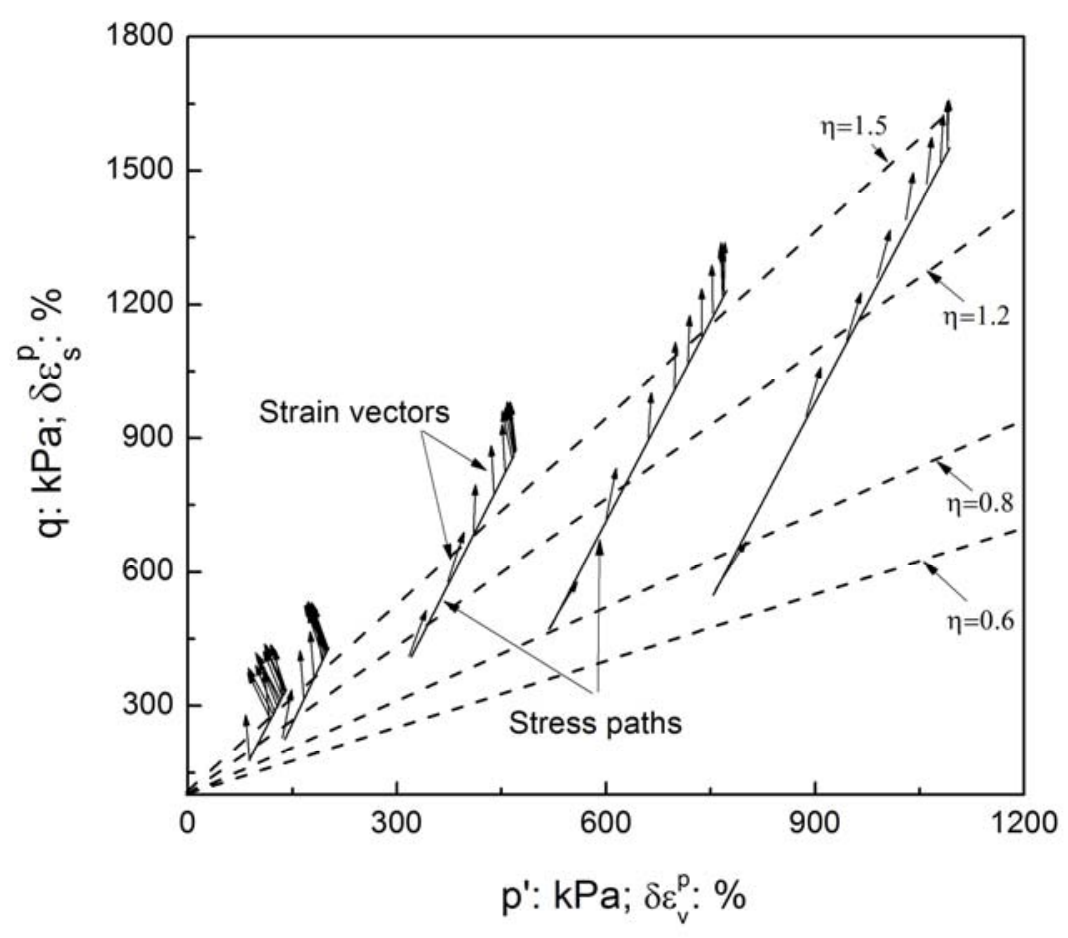

Fig. 7. Incremental plastic strain vectors along stress paths. 


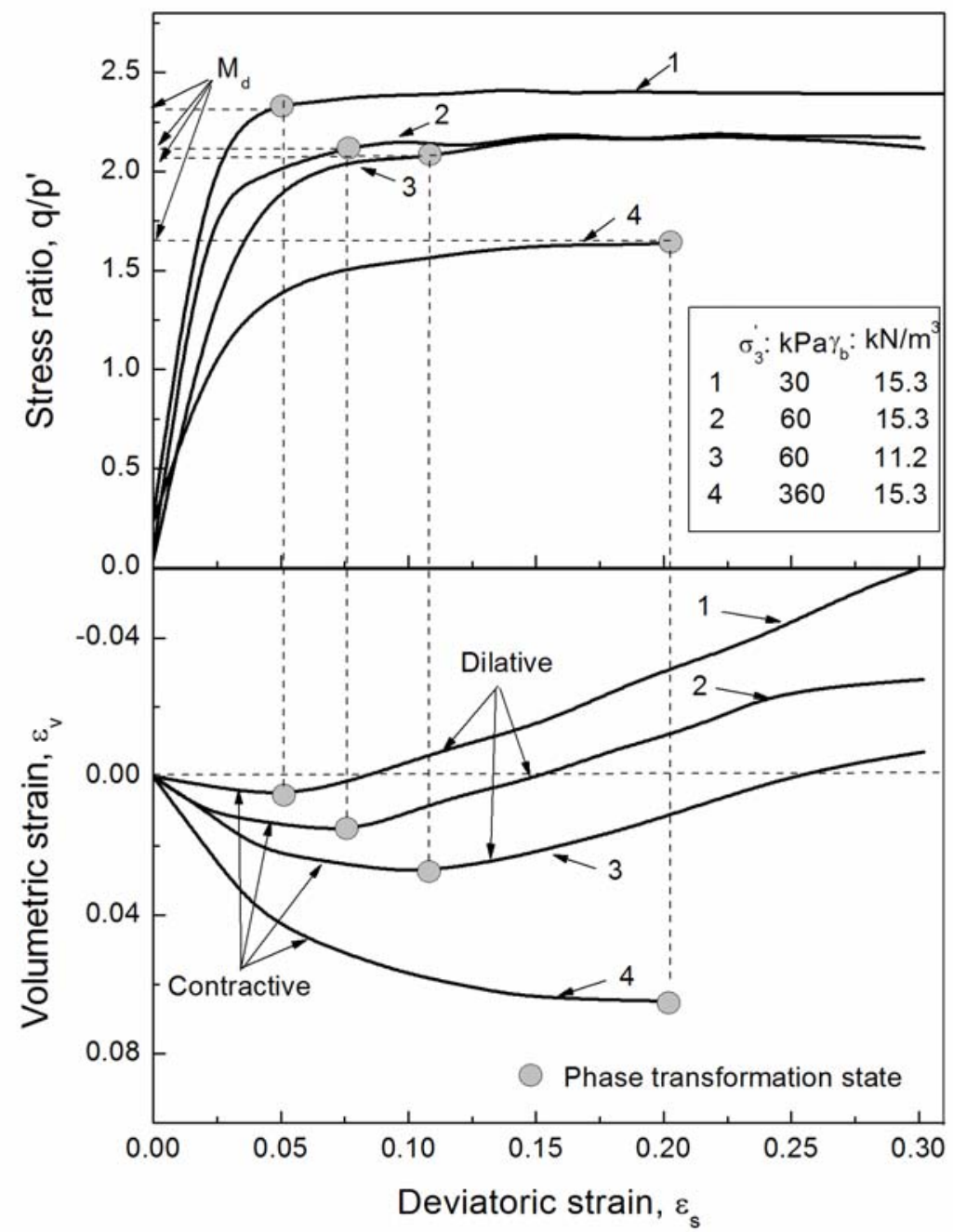

Fig. 8. Variation in dilatancy with material state. 


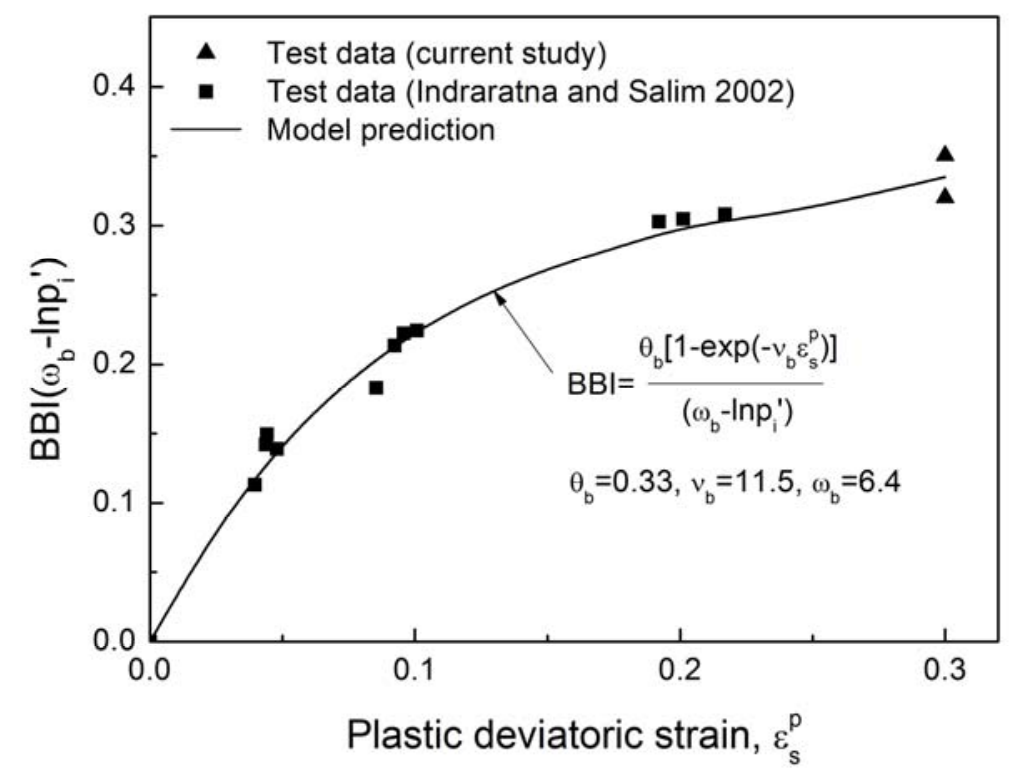

Fig. 9. Particle breakage parameters (data sourced from Indraratna and Salim 2002). 


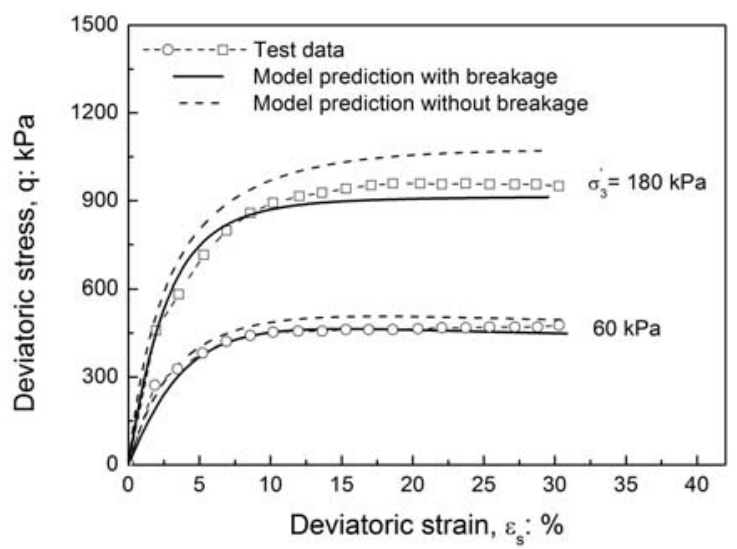

(a)

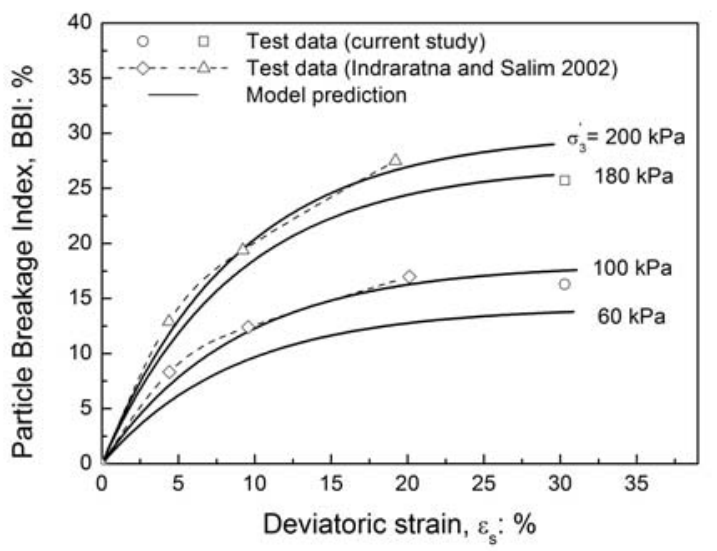

(c)

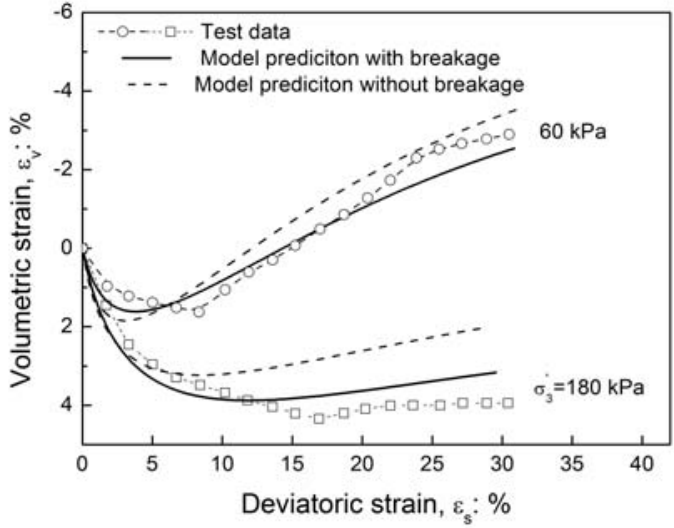

(b)

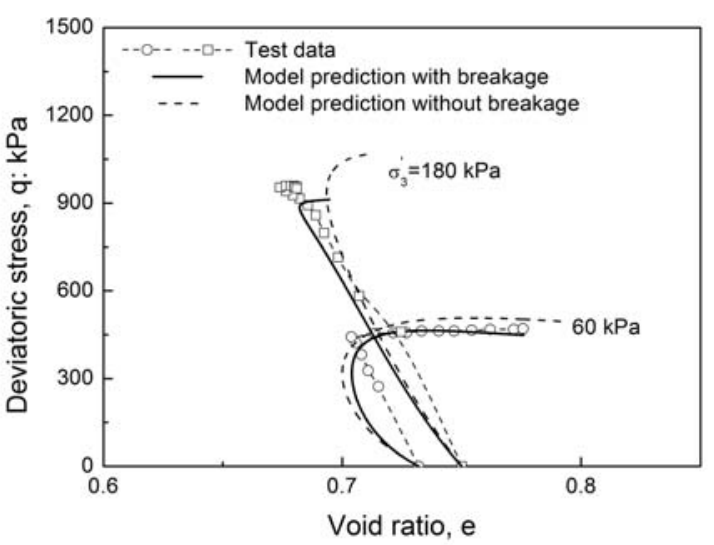

(d)

Fig. 10. Model predictions compared with experimental results of drained triaxial shearing:

(a) stress-strain response, (b) volume change behaviour, (c) particle breakage predictions and (d) void ratio. 


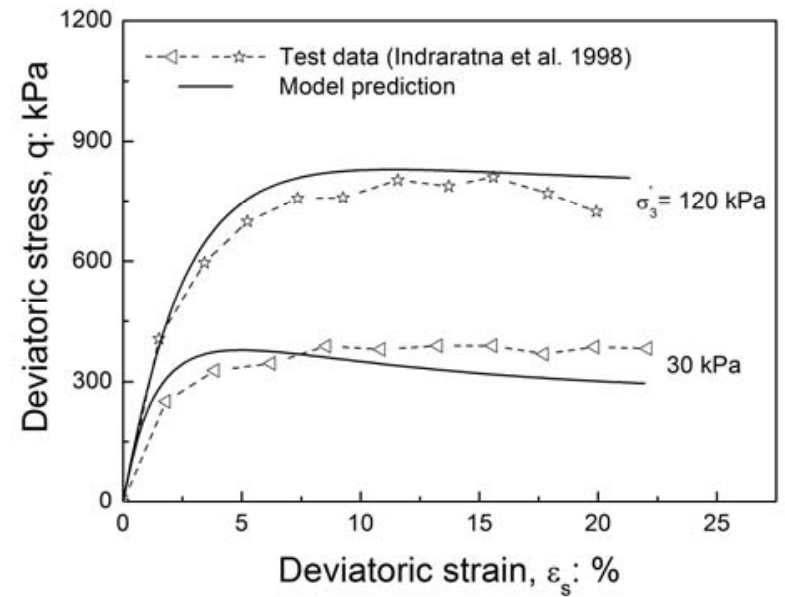

(a)

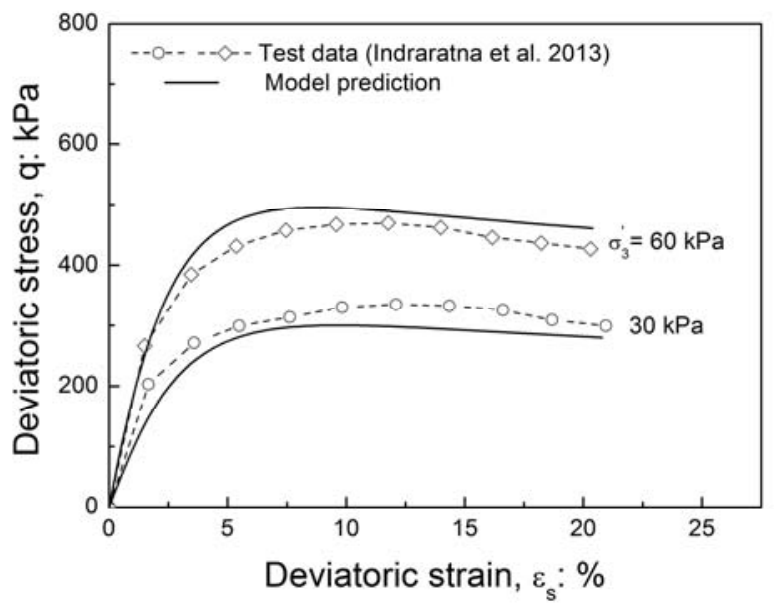

(c)

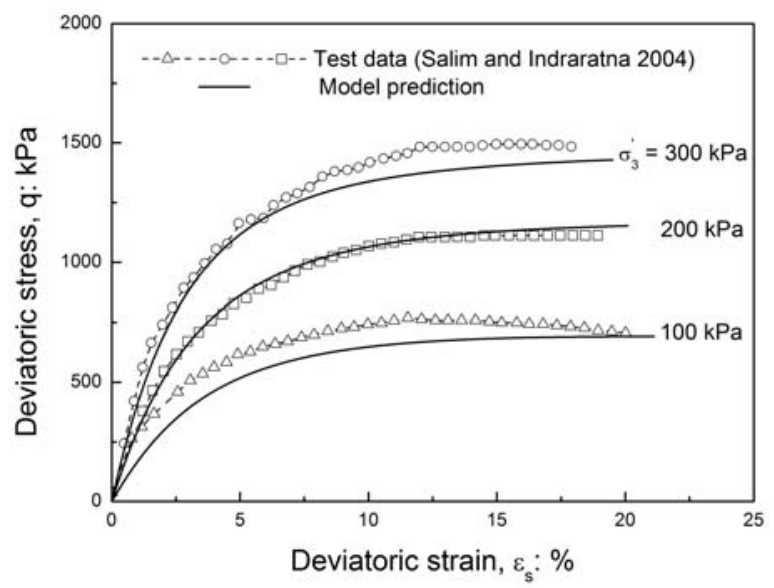

(e)

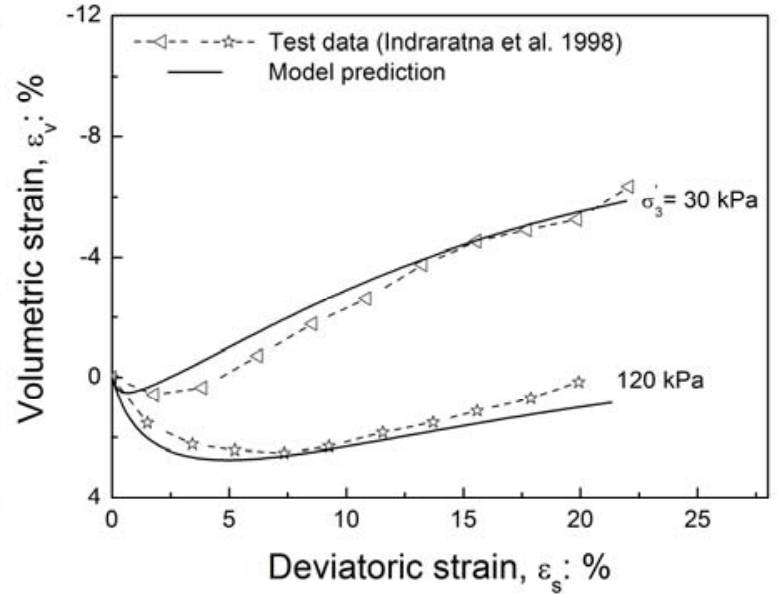

(b)

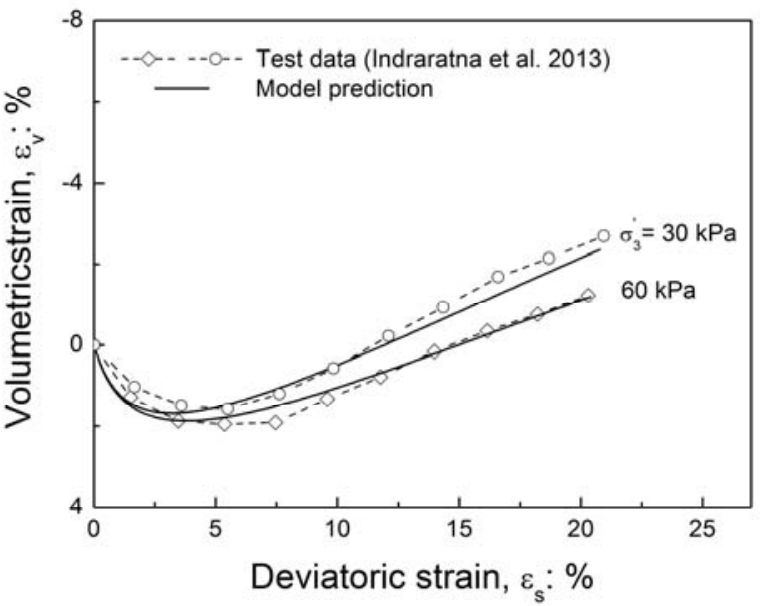

(d)

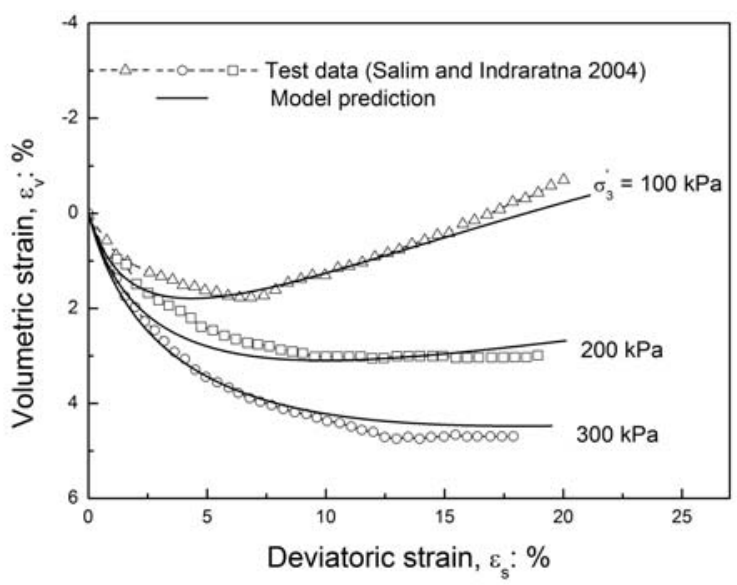

(f)

Fig. 11. Model predictions compared with experimental results of drained triaxial shearing (data sourced from Indraratna et al. 1998, 2013; Salim and Indraratna 2004). 


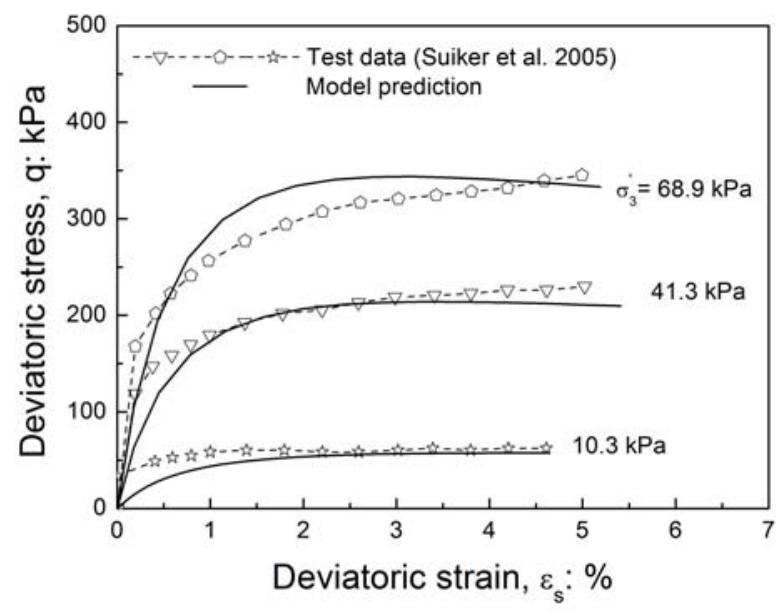

(a)

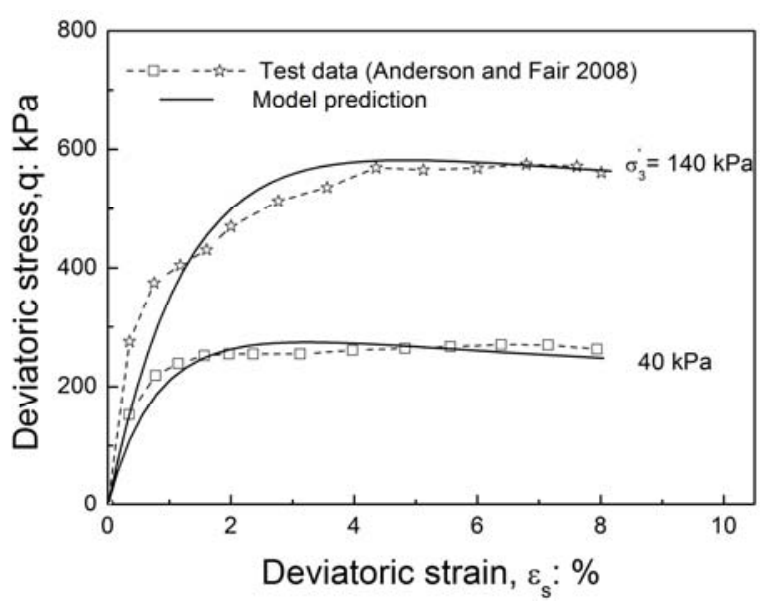

(c)

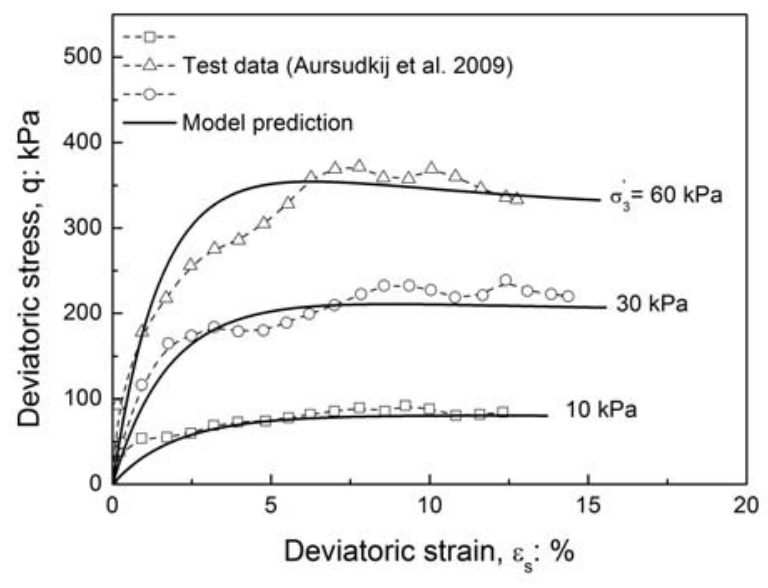

(e)

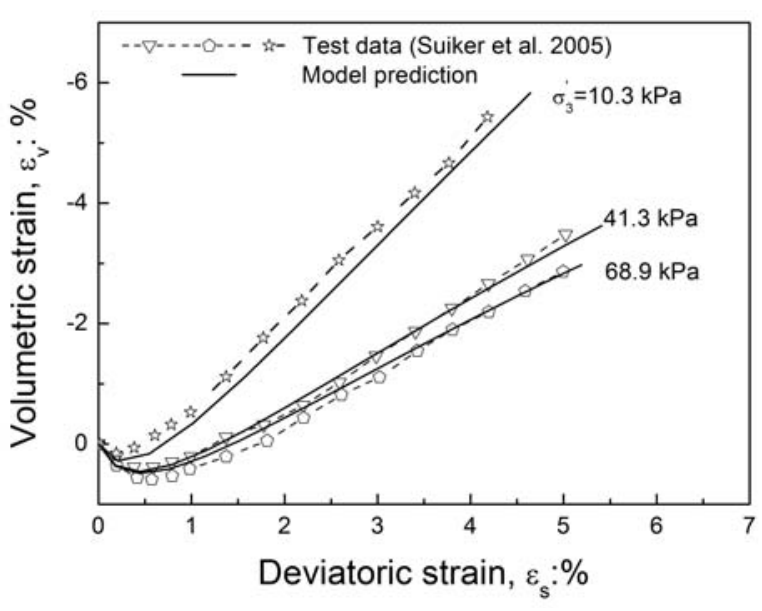

(b)

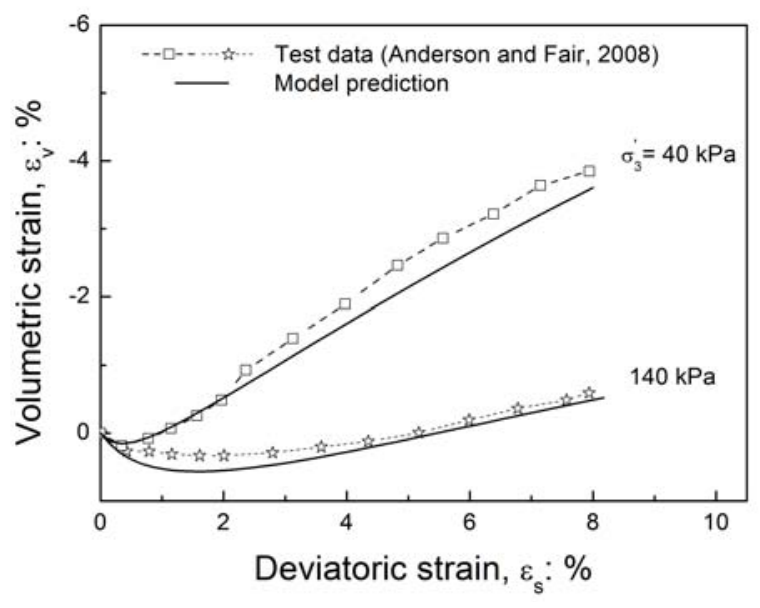

(d)

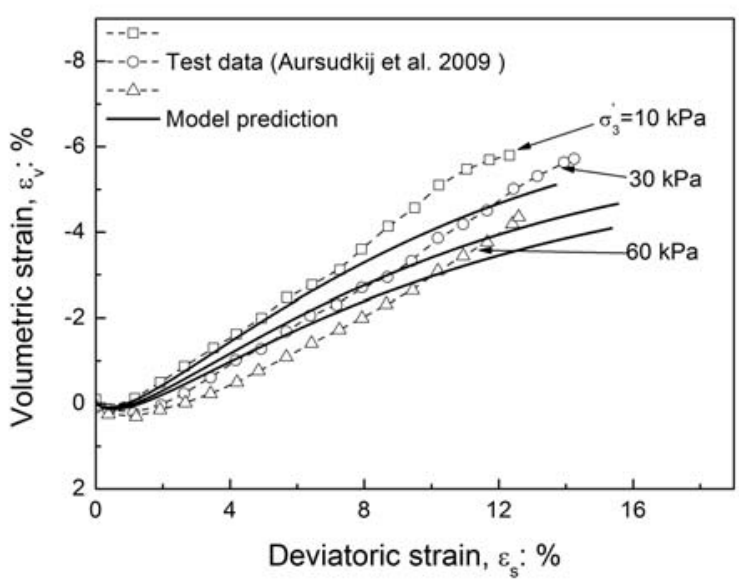

(f)

Fig. 12. Model predictions compared with experimental results of drained triaxial shearing (data sourced from Suiker et al. 2005; Anderson and Fair 2008; Aursudkij et al. 2009). 


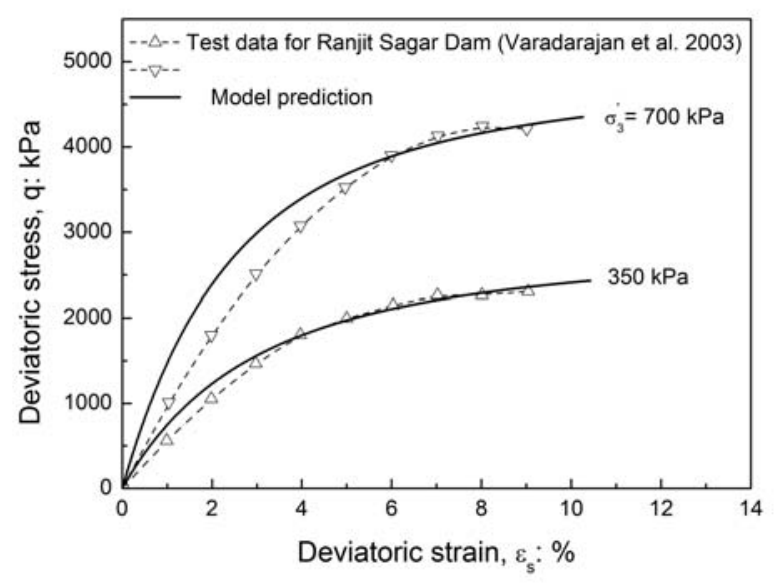

(a)

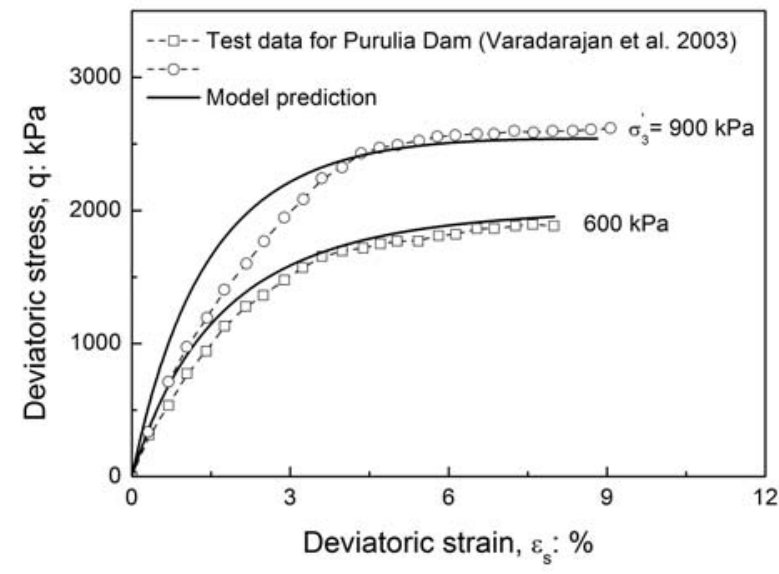

(c)

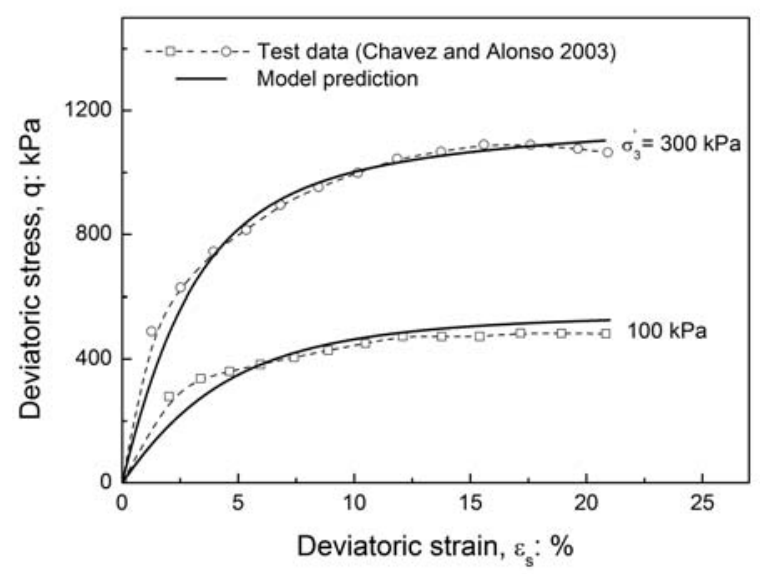

(e)

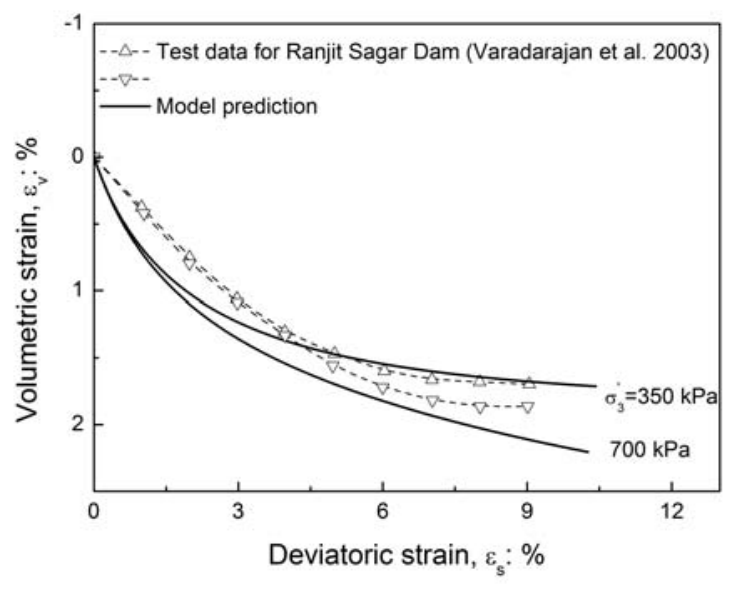

(b)

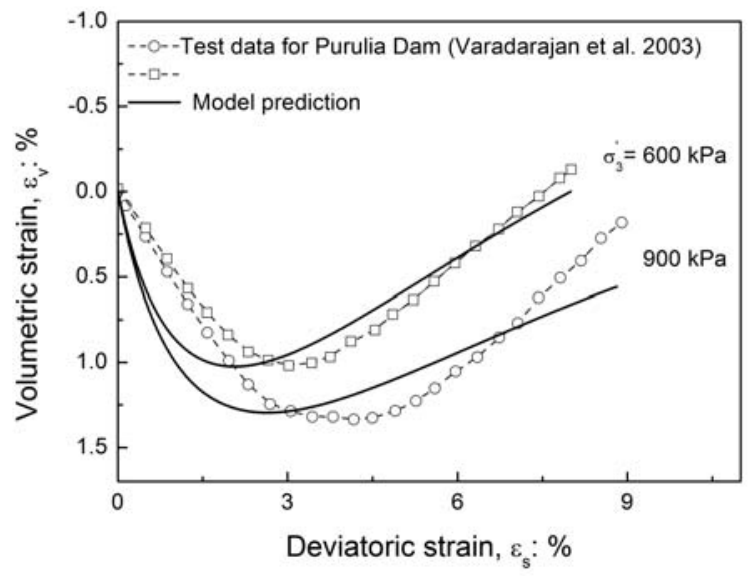

(d)

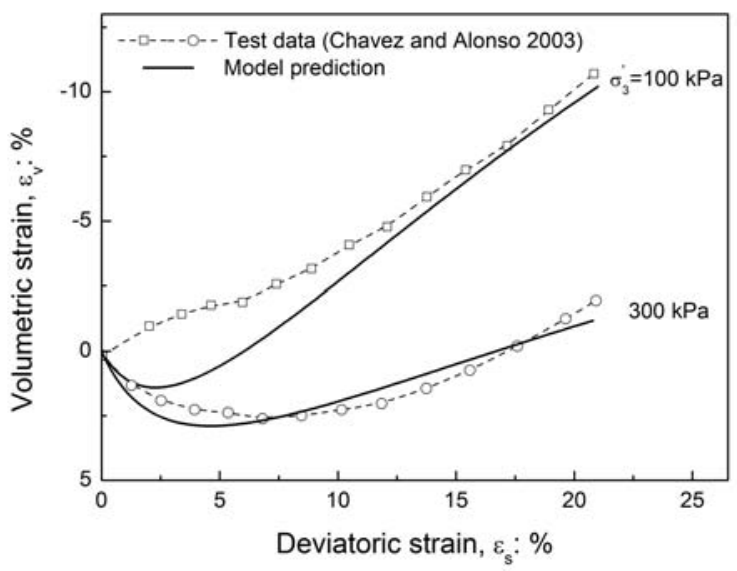

(f)

Fig. 13. Model predictions compared with experimental results of drained triaxial shearing for rockfill materials (data sourced from Varadarajan et al. 2003; Chavez and Alonso 2003). 


\section{Appendix A: Example of estimation of critical state}

Figure A1(a) shows an example of a test $\left(\sigma_{3}{ }^{\prime}=60 \mathrm{kPa}\right)$ that was stopped when the volumetric strain was still changing slightly. The value of stress ratio at the critical state, $\left(q / p^{\prime}\right)_{c s}$, has been predicted from the stress-dilatancy graph (Fig. A1(b)) for the test, extending the last part of the curve to the point of intersection with the zero dilatancy axis (Carrera et al. 2011). The rate of volumetric strain, $\delta \varepsilon_{v} / \delta \varepsilon_{s}$, plotted against the stress ratio was used to assess dilatancy, where $\varepsilon_{v}$ is volumetric strain and $\varepsilon_{s}$ is deviatoric strain. The $\left(q / p^{\prime}\right)_{c s}$ value was determined as 2.17 .

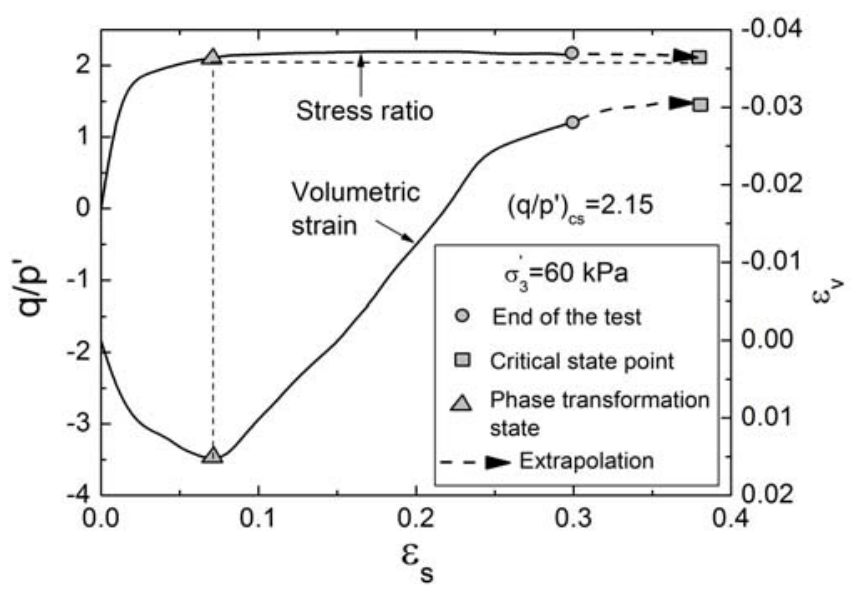

(a)

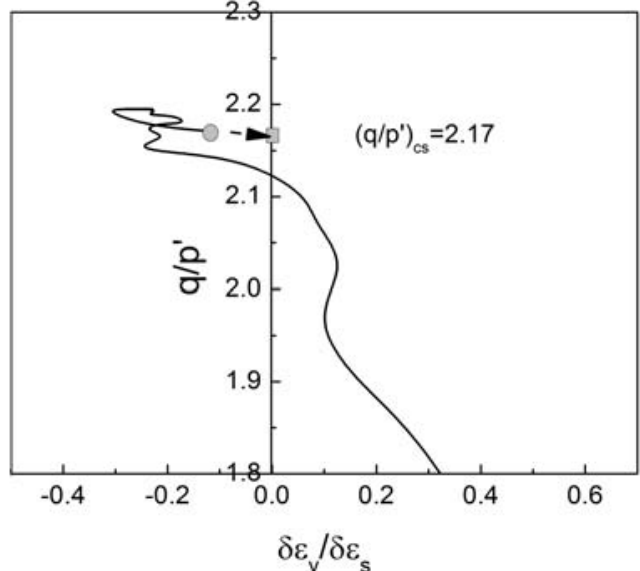

(b)

Fig. A1. (a) An example of test $\left(\sigma_{3}{ }^{\prime}=60 \mathrm{kPa}\right)$ that ended before reaching the critical state; (b) estimation of the critical state stress ratio by means of stress-dilatancy based approach.

The separation between the region of compression and the region of dilation for drained tests on ballast occurs at the phase transformation state at which dilatancy $\delta \varepsilon_{v} / \delta \varepsilon_{s}=0$, as shown in Fig. A1(a). The phase transformation state and the critical state are very similar, as discussed by Luong (1982). For dense ballast or ballast at low confining pressure, the phase transformation state is reached at small strain magnitudes, as indicated in Fig. A1(a), while 
the critical state is reached at large strains. Hence, the phase transformation state can be used to give the most appropriate value of $\left(q / p^{\prime}\right)_{c s}$ which was determined as 2.15. 


\section{Appendix B: Derivation of $\boldsymbol{H}$}

According to generalized plasticity, hardening modulus is defined as:

[B1]

$$
H=-\frac{\partial f}{\partial \eta_{s}} \frac{\partial \eta_{s}}{\partial \varepsilon_{s}^{p}} \frac{\partial g}{\partial q}
$$

The linear yield function is expressed as:

$$
f=q / p^{\prime}-\eta_{s}=0
$$

where,

$$
\eta_{s}=\frac{\varepsilon_{s}^{p}}{B_{m}+\varepsilon_{s}^{p}} M_{c}\left(1-k_{p} \psi\right)
$$

Partial differentiation of eq. [B2] yields:

[B4]

$$
\partial f / \partial \eta_{s}=-1
$$

Partial differentiation of eq. [B3] gives:

[B5] $\frac{\partial \eta_{s}}{\partial \varepsilon_{s}^{p}}=\partial\left(\frac{\varepsilon_{s}^{p}}{B_{m}+\varepsilon_{s}^{p}}\right) / \partial \varepsilon_{s}^{p} M_{c}\left(1-k_{p} \psi\right)+\frac{\varepsilon_{s}^{p}}{B_{m}+\varepsilon_{s}^{p}} \frac{\partial M_{c}}{\partial \varepsilon_{s}^{p}}\left(1-k_{p} \psi\right)+\frac{\varepsilon_{s}^{p}}{B_{m}+\varepsilon_{s}^{p}} M_{c} \frac{\partial\left(1-k_{p} \psi\right)}{\partial \varepsilon_{s}^{p}}$

with,

[B6]

$$
\partial\left(\frac{\varepsilon_{s}^{p}}{B_{m}+\varepsilon_{s}^{p}}\right) / \partial \varepsilon_{s}^{p}=\frac{B_{m}}{\left(B_{m}+\varepsilon_{s}^{p}\right)^{2}}
$$

Critical state stress ratio can be expressed:

[B7]

$$
M_{c}=M_{c 0}-\left\{1-\exp \left[-\alpha \frac{\theta_{b}\left(1-\exp \left(-v_{b} \varepsilon_{s}^{p}\right)\right)}{\omega_{b}-\ln p_{i}^{\prime}}\right]\right\}
$$

Partial differentiation of eq. [B7] gives:

$[\mathrm{B} 8]$

$$
\frac{\partial M_{c}}{\partial \varepsilon_{s}^{p}}=-\frac{\alpha \theta_{b} v_{b}}{\omega_{b}-\ln p_{i}^{\prime}} \exp \left(-v_{b} \varepsilon_{s}^{p}\right) \exp \left\{-\alpha \frac{\theta_{b}\left[1-\exp \left(-v_{b} \varepsilon_{s}^{p}\right)\right]}{\omega_{b}-\ln p_{i}^{\prime}}\right\}
$$

The state parameter is expressed as: 
[B9]

$$
\psi=v-\Gamma_{r e f}+a \cdot \exp \left\{b \cdot \frac{\theta_{b}\left[1-\exp \left(-v_{b} \varepsilon_{s}^{p}\right)\right]}{\omega_{b}-\ln p_{i}^{\prime}}\right\}+\lambda \ln p^{\prime}
$$

Substituting eq. [B9] into expression $1-k_{p} \psi$ and taking partial differentiation of it give:

[B10] $\frac{\partial\left(1-k_{p} \psi\right)}{\partial \varepsilon_{s}^{p}}=-\frac{k_{p} a b \theta_{b} v_{b}}{\omega_{b}-\ln p_{i}^{\prime}} \exp \left(-v_{b} \varepsilon_{s}^{p}\right) \exp \left\{b \frac{\theta_{b}\left[1-\exp \left(-v_{b} \varepsilon_{s}^{p}\right)\right]}{\omega_{b}-\ln p_{i}^{\prime}}\right\}$

Third term in eq. [B1] can be expressed as:

[B11] $\quad \frac{\partial g}{\partial q}=1$

where $g$ is the plastic potential function.

Substituting eqs. [B4], [B5] and [B11] into eq. [B1], $H$ is expressed as:

[B12]

$$
\begin{aligned}
& H=\frac{1}{\left(B_{m}+\varepsilon_{s}^{p}\right)}\left\{\frac{B_{m} M_{c}\left(1-k_{p} \psi\right)}{B_{m}+\varepsilon_{s}^{p}}-\frac{\varepsilon_{s}^{p} \theta_{b} v_{b}}{\omega_{b}-\ln p_{i}^{\prime}} \exp \left(-v_{b} \varepsilon_{s}^{p}\right)\left\{\alpha\left(1-k_{p} \psi\right) \exp \left\{-\frac{\alpha \theta_{b}\left[1-\exp \left(-v_{b} \varepsilon_{s}^{p}\right)\right]}{\omega_{b}-\ln p_{i}^{\prime}}\right\}\right.\right. \\
& \left.\left.+M_{c} \exp \left\{\frac{b \theta_{b}\left[1-\exp \left(-v_{b} \varepsilon_{s}^{p}\right)\right]}{\omega_{b}-\ln p_{i}^{\prime}}\right\}\right\}\right\}
\end{aligned}
$$




\section{Appendix C: Determination of elastic shear modulus $G$}

The elastic shear modulus $G$, can be evaluated from stress-strain data of triaxial shearing, as shown in Fig. C1. The initial small $q-\varepsilon_{s}$ plot gives the value of $3 G$. Shear modulus $G$ can be determined by:

[C1] $\quad G=\frac{\delta q}{3 \cdot \delta \varepsilon_{s}}$

where $\delta q$ and $\delta \varepsilon_{s}$ are increments of stress and strain separately.

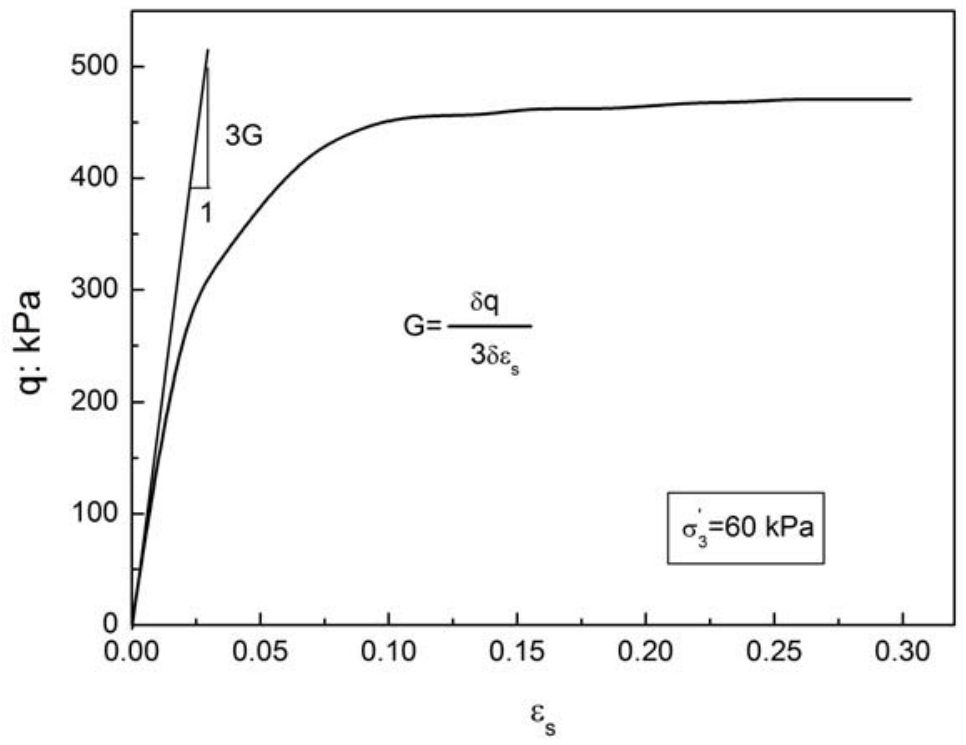

Fig. C1. Determination of shear modulus $G$. 